\title{
Non-Thermal Plasma for Process and Energy Intensification in Dry Reforming of Methane
}

\author{
Rufat Sh. Abiev 1,*®D, Dmitry A. Sladkovskiy ${ }^{2}$, Kirill V. Semikin ${ }^{2}$, Dmitry Yu. Murzin ${ }^{2,3}$ \\ and Evgeny V. Rebrov 1,4,5 $\mathbb{D}$ \\ 1 Department of Optimization of Chemical and Biotechnological Equipment, St. Petersburg State Institute of \\ Technology (Technical University), St. Petersburg 190013, Russia; E.Rebrov@warwick.ac.uk \\ 2 Resource-Saving Department, St. Petersburg State Institute of Technology (Technical University), \\ St. Petersburg 190013, Russia; dmitry.sla@gmail.com (D.A.S.); kirrse@gmail.com (K.V.S.) ; \\ Dmitry.Murzin@abo.fi (D.Y.M.) \\ 3 Laboratory of Industrial Chemistry and Reaction Engineering, Åbo Akademi University, \\ FI-20500 Åbo (Turku), Finland \\ 4 School of Engineering, University of Warwick, Coventry CV4 7AL, UK \\ 5 Department of Chemical Engineering and Chemistry, Eindhoven University of Technology, \\ P.O. Box 513, 5600 MB Eindhoven, The Netherlands \\ * Correspondence: ohba@lti-gti.ru or abiev.rufat@gmail.com
}

Received: 2 October 2020; Accepted: 17 November 2020; Published: 22 November 2020

check for updates

\begin{abstract}
Plasma-assisted dry reforming of methane (DRM) is considered as a potential way to convert natural gas into fuels and chemicals under near ambient temperature and pressure; particularly for distributed processes based on renewable energy. Both catalytic and photocatalytic technologies have been applied for DRM to investigate the $\mathrm{CH}_{4}$ conversion and the energy efficiency of the process. For conventional catalysis; metaldoped Ni-based catalysts are proposed as a leading vector for further development. However; coke deposition leads to fast deactivation of catalysts which limits the catalyst lifetime. Photocatalysis in combination with non-thermal plasma (NTP), on the other hand; is an enabling technology to convert $\mathrm{CH}_{4}$ to more reactive intermediates. Placing the catalyst directly in the plasma zone or using post-plasma photocatalysis could generate a synergistic effect to increase the formation of the desired products. In this review; the recent progress in the area of NTP-(photo)catalysis applications for DRM has been described; with an in-depth discussion of novel plasma reactor types and operational conditions including employment of ferroelectric materials and nanosecond-pulse discharges. Finally, recent developments in the area of optical diagnostic tools for NTP, such as optical emission spectroscopy (OES), in-situ FTIR, and tunable diode laser absorption spectroscopy (TDLAS), are reviewed.
\end{abstract}

Keywords: photocatalyst; non-thermal plasma; post-plasma catalysis; dry reforming of methane; optical emission spectroscopy; dielectric barrier discharge; plasma jet reactor; pulsed plasma jet; ferroelectrics; syngas; energy efficiency

\section{Introduction}

Natural gas is an abundant, cheap, and underutilized resource with increasing proved reserves. It is mainly used as a source of energy for heating and power generation. Methane is the principal component of natural gas with a volumetric fraction of more than $75 \%$ [1]. Increasing worldwide energy demands with the discovery of huge shale deposits stimulated extensive research in the conversion of natural gas to high-value transportation fuels and chemicals.

On the other size, $\mathrm{CO}_{2}$ is increasingly utilized in many applications. For example, in Iceland, a pioneering $\mathrm{CO}_{2}$ to methanol plant using locally available cheap geo-thermal energy has been built by 
Carbon Recycling International company. In Canada, Blue Fuel Energy will build a $\mathrm{CO}_{2}$ to methanol plant with a capacity of 400,000 tons per year, powered by renewable electricity [2].

Conventional thermo-catalytic approaches focus on converting methane to syngas [3,4], ethane and ethylene [5], or $C_{1}$ oxygenates [6]. It should be mentioned that along with commercially used technologies (like e.g., steam and autothermal reforming methane to syngas) some other promising methods are on the lab-scale level (such as dry reforming or methane coupling). High temperature $\left(>600^{\circ} \mathrm{C}\right.$ ) is used in dry reforming reactors to facilitate reactions, leading to severe coke formation and a relatively low yield of the desired products. A close to equilibrium yield is easily attainable over a wide range of catalysts.

Photo- and plasma catalysis are potential technologies to enable methane activation to more reactive intermediates. These technologies are also studied for their application towards $\mathrm{CO}_{2}$ reduction to fuels and chemicals. Although the direct use of solar energy to convert $\mathrm{CO}_{2}$ and/or $\mathrm{CH}_{4}$ is feasible via photocatalytic processes, low conversion efficiency and limited use of the full solar spectrum are major drawbacks of this approach. While this is an attractive option, the main problems are related to the low productivity and the combined (in a single compartment) formation of products of reduction and oxidation, creating issues of safety (creation of explosive mixtures in a reaction compartment) as well as high costs of separation. Although many research groups are working in this direction, the industrial applications of this method are foreseen only in a rather distant future. Conventional photocatalytic reactions occur at a gas-solid interface and therefore limited by available surface area. Often, liquid products can form a film that prevents the efficient mass transfer of gas molecules to the surface. Furthermore, the light intensity decreases with increasing the thickness of the photocatalytic layer. Therefore reaction interface engineering is highly desirable to understand in order to enhance the photocatalytic kinetics. However, it has received relatively little attention with respect to catalyst design [7]. Therefore in the present form, photocatalytic processes are relatively inefficient and, thus, are unlikely to compete with large-scale industrial chemical processes in short and midterm. However, their ability to produce fuels paves the way for the potential storage of solar energy, which could not be utilized otherwise [8,9].

Another alternative approach is to apply solar radiation to provide the heat (above $1200^{\circ} \mathrm{C}$ ) for $\mathrm{CO}_{2}$ decomposition reaction to generate $\mathrm{CO}$ (or $\mathrm{CH}_{4}$ decomposition reaction to generate $\mathrm{H}_{2}$ ), rather than to generate charge separation and photoinduced electrical current. A concept of concentrated solar power (CSP) plants with metal oxides was a hot research topic a few years ago. Despite many research problems were solved, many others remained and those are related to limited production scale, material stability at high temperatures, and high equipment costs. These factors strongly hinder further development beyond the pilot plant scale, and current interest on this route is decreasing.

Plasma assisted catalysis, on the other hand, is able to convert large amounts of $\mathrm{CO}_{2}$ and $\mathrm{CH}_{4}$ via electrical energy attracting significant attention due to its mild operating conditions and unique advantages in activating inert molecules. Because of the non-equilibrium characteristics, non-thermal plasma (NTP) promotes thermodynamically unfavorable chemical reactions to occur at relatively low temperatures [10]. However, due to high reactivity of plasma, producing a diversity of activated species, radicals and ions, the process lacks selectivity towards the specific end products. Placing the catalyst directly in the plasma zone or using post-plasma catalysis could generate a synergistic effect to increase the formation of the desired products. The synergistic effect between NTP and the catalyst on the yield of liquid fuels chemicals was previously reported in dry reforming of methane (DRM) [11].

Over the last 5 years, several reviews covering $\mathrm{CH}_{4}$ activation in plasma have been published. Chung and Chang discussed plasma-catalysis interactions in DRM reaction and possible synergy mechanisms [12]. The review of Puliyalil et al. made an overview of different reaction pathways, related to the partial oxidation steps of $\mathrm{CH}_{4}$ and $\mathrm{CO}_{2}$ as well as $\mathrm{CO}_{2}$ reduction with $\mathrm{H}_{2}, \mathrm{CH}_{4}$ or other paraffin species to syngas [13]. Shao et al. published a review on the application of nanosecond pulsed discharges for the activation of small molecules [14]. Recent progress on the mechanism of nanosecond-pulse discharge based on runaway electrons and related measurement technology was 
discussed and the characteristics of three typical discharges, including direct-driven pulsed discharge, pulsed dielectric barrier discharge and pulsed plasma jet, were reviewed. The authors argued that classical Townsend and streamer theories cannot be applied to pulsed discharge.

Our paper aims to provide a view on the future development for a scientist or an engineer who wants to understand the role of plasma technology in the new scenario of distributed energy production for a sustainable and low-carbon economy. Therefore, first, we introduce the current state-of-the-art and the potential of $\mathrm{CH}_{4}$ conversion technologies. This section is a snapshot of current research activities in different research groups and it is not intended to give a complete picture over current (thermos-chemical) methods of $\mathrm{CH}_{4}$ activation. Then the paper describes main plasma reactor types used in the DRM reaction with a detailed view on the application of dielectric barrier discharge reactors. This is followed by an overview of applications of ferroelectric and/or catalytic materials and examples of synergistic effects between NTP and relevant catalysts. Photocatalysis is often considered as an important step towards further developments in the plasma-catalysis field. Therefore, we introduced a section describing photocatalytic applications for $\mathrm{CH}_{4}$ activation. Finally, the recent developments in the area of plasma diagnostic methods are reviewed and discussed. In the outlook section, we discussed the potential benefits of plasma-based $\mathrm{CH}_{4}$ conversion and its impact on distributed energy production and climate change.

\section{State of the Art in DRM}

\subsection{Conventional Thermo-Catalytic Methane Dry Reforming}

DRM is a highly endothermic reaction requiring high energy input. The process temperature occurs typically above $700{ }^{\circ} \mathrm{C}$, and in some cases even at high $\mathrm{T}$ as $850{ }^{\circ} \mathrm{C}$ [15]. At the same time, there is no direct involvement of oxygen leading to carbon deposition on the catalyst surface [16]. Possible reactions involved in the DRM process are listed below [17]:

$$
\begin{gathered}
\mathrm{CH}_{4}+\mathrm{CO}_{2} \leftrightarrow 2 \mathrm{CO}+2 \mathrm{H}_{2}+247 \mathrm{~kJ} \mathrm{~mol}^{-1} \\
\mathrm{CO}+\mathrm{H}_{2} \leftrightarrow \mathrm{H}_{2} \mathrm{O}+\mathrm{C}-131.3 \mathrm{~kJ} \mathrm{~mol}^{-1} \\
\mathrm{CO}_{2}+2 \mathrm{H}_{2} \leftrightarrow \mathrm{C}+2 \mathrm{H}_{2} \mathrm{O}-90 \mathrm{~kJ} \mathrm{~mol}^{-1} \\
\mathrm{CH}_{4} \leftrightarrow \mathrm{C}+2 \mathrm{H}_{2}+74.9 \mathrm{~kJ} \mathrm{~mol}^{-1} \\
2 \mathrm{CO} \leftrightarrow \mathrm{C}+\mathrm{CO}_{2}-172.9 \mathrm{~kJ} \mathrm{~mol}^{-1} \\
\mathrm{CO}_{2}+\mathrm{H}_{2} \leftrightarrow \mathrm{CO}+\mathrm{H}_{2} \mathrm{O}+41 \mathrm{~kJ} \mathrm{~mol}^{-1}
\end{gathered}
$$

Besides hydrogenation of $\mathrm{CO}$ (entry 2) and $\mathrm{CO}_{2}$ (entry 3) leading to coke, the later can also be produced by the decomposition of methane (entry 4 ) or the Boudouard reaction (entry 5). The main challenge is, therefore, to suppress the undesired reactions by application of more selective catalysts $[18,19]$.

Different solid catalysts used in DRM and the related reaction conditions are listed in Table 1. For more information on thermo-catalytic the reader is referred to several reviews available in the literature [20-22] In general, noble metal catalysts (namely, $\mathrm{Pt}, \mathrm{Ru}$, and $\mathrm{Rh}$ ) provide enhanced lifetime with a high catalytic activity [23]. Nonetheless, even for $\mathrm{Pt}$ on alumina catalysts, deactivation remains significant [24]. The addition of small amounts of ceria along with $\mathrm{Pr}, \mathrm{Zr}$ or Nb as dopants to $\mathrm{Pt} / \mathrm{Al}_{2} \mathrm{O}_{3}$ catalyst improved the catalyst lifetime, at the expense of much higher catalyst costs.

Industrially preferred $\mathrm{Ni}$ - and $\mathrm{Co}$-based catalysts have been extensively studied from the viewpoint of selecting suitable promoters, catalyst supports, as well as preparation methods and the optimal metal content [20-22]. The effect of different supports, such as $\mathrm{Al}_{2} \mathrm{O}_{3}, \mathrm{SiO}_{2}, \mathrm{MgO}, \mathrm{TiO}_{2}$ and $\mathrm{ZrO}_{2}$, on the activity of supported $\mathrm{Ni}$ catalysts was investigated [25]. A Ni/TiO ${ }_{2}$ catalyst showed the highest reaction rate, with the activity decreased as follows: $\mathrm{SiO}_{2}<\mathrm{MgO}<\mathrm{Al}_{2} \mathrm{O}_{3}<\mathrm{ZrO}_{2}<\mathrm{TiO}_{2}$. 
The catalyst deactivation by rapid coke deposition was diminished by an addition of reducible supports to Ni catalysts enhance the oxygen storage capacity and thus the catalyst lifetime. Due to their basicity and high oxygen storage capacity, reducible oxides such as $\mathrm{CeO}_{2}$ and $\mathrm{La}_{2} \mathrm{O}_{3}$ decreased the coke deposition rate and improved the catalytic lifetime [26,27]. A $5 \mathrm{wt} . \% \mathrm{CeO}_{2} / 25 \mathrm{wt} . \% \mathrm{Ni} / \mathrm{Al}_{2} \mathrm{O}_{3}$ composite catalyst, prepared by ultrasonic-assisted co-precipitation, was stable during $15 \mathrm{~h}$ on-stream [27]. Addition of rare-earth elements further improved the catalytic activity of Ni catalysts. The largest positive effect was achieved with an addition of Ce, followed by Pr and Y. The smallest effect was observed with the addition of Sc, yet the catalyst was still more active compared to the unpromoted one. The carbon deposition decreased by $25 \%$ over Ce-promoted catalysts due to enhanced surface basicity and higher Ni dispersion. In addition, both Ce- and Pr-modified catalysts demonstrated fast redox behavior that involved the reversible formation of $\mathrm{Ce}^{3+} / \mathrm{Ce}^{4+}$ and $\mathrm{Pr}^{3+} / \mathrm{Pr}^{4+}$ redox pairs, facilitating their decoking.

Table 1. Comparison of catalytic activity of different catalysts studied in thermo-catalytic dry reforming of methane (DRM) process.

\begin{tabular}{|c|c|c|c|c|c|c|c|}
\hline \multirow{2}{*}{ Catalysts } & \multirow{2}{*}{$\operatorname{Temp}\left({ }^{\circ} \mathrm{C}\right)$} & \multirow{2}{*}{ TOS (h) } & \multirow{2}{*}{$\begin{array}{l}\text { GHSV (L } \\
\left.\text { gcat }^{-1} h^{-1}\right)\end{array}$} & \multicolumn{2}{|c|}{ Conversion $(\%)$} & \multirow{2}{*}{$\begin{array}{c}\mathrm{H}_{2} / \mathrm{CO} \\
\text { Ratio } \\
\text { (Molar) }\end{array}$} & \multirow{2}{*}{ Ref. } \\
\hline & & & & $\mathrm{CH}_{4}$ & $\mathrm{CO}_{2}$ & & \\
\hline $\mathrm{Mo}-\mathrm{Ni} / \mathrm{Al}_{2} \mathrm{O}_{3}$ & 600 & 7 & 200 & 22 & 30 & 0.60 & [28] \\
\hline $\mathrm{Co}-\mathrm{Zr} / \mathrm{AC}$ & 600 & 45 & 7 & 89 & 89 & - & [29] \\
\hline $\mathrm{Co}-\mathrm{Ni} / \mathrm{Al}_{2} \mathrm{O}_{3}-\mathrm{MgO}$ & 850 & 20 & 24 & 92 & 95 & 0.97 & [30] \\
\hline $\mathrm{Pd}-\mathrm{Ni} / \mathrm{Al}_{2} \mathrm{O}_{3}$ & 750 & 100 & 8 & 85 & 83 & 1.03 & [31] \\
\hline $\mathrm{Co}_{3} \mathrm{Mo}_{3} \mathrm{~N}$ & 800 & 50 & 6 & 87 & 98 & 0.83 & [32] \\
\hline $\mathrm{Co}-\mathrm{Ni} / \mathrm{Al}_{2} \mathrm{O}_{3}$ & 600 & 180 & - & 16 & 18 & 0.46 & [33] \\
\hline $\mathrm{Pt} / \mathrm{Al}_{2} \mathrm{O}_{3}$ & 800 & 24 & - & 17 & 20 & 0.53 & [24] \\
\hline $\mathrm{Pt} / \mathrm{CePr} / \mathrm{Al}_{2} \mathrm{O}_{3}$ & 800 & 24 & - & 59 & 69 & 0.81 & [24] \\
\hline $\mathrm{Pt} / \mathrm{CeNb} / \mathrm{Al}_{2} \mathrm{O}_{3}$ & 800 & 24 & - & 40 & 52 & 0.59 & [24] \\
\hline $\mathrm{Pt} / \mathrm{CeZr} / \mathrm{Al}_{2} \mathrm{O}_{3}$ & 800 & 24 & - & 42 & 55 & 0.70 & [24] \\
\hline $\mathrm{Ni} / \mathrm{Al}_{2} \mathrm{O}_{3}$ & 800 & 8 & 120 & 65 & 70 & 0.89 & [34] \\
\hline $\mathrm{Ni} / \mathrm{Al}_{2} \mathrm{O}_{3}-\mathrm{CeO}_{2}$ & 800 & 8 & 120 & 82 & 89 & 0.94 & [34] \\
\hline $\mathrm{Ni} / \mathrm{Al}_{2} \mathrm{O}_{3}-\mathrm{La}_{2} \mathrm{O}_{3}$ & 800 & 8 & 120 & 67 & 80 & 0.87 & [34] \\
\hline $\mathrm{Ni} / \mathrm{MgAl}_{2} \mathrm{O}_{4}$ & 700 & 15 & 18 & 70.6 & 81.2 & - & [35] \\
\hline $\mathrm{Ni}-\mathrm{MgO}-\mathrm{Al}_{2} \mathrm{O}_{3}$ & 700 & 12 & 180 & 71.4 & 79.8 & 0.92 & [36] \\
\hline
\end{tabular}

\subsection{Application of Non-Thermal Plasma and Catalysis for DRM}

Due to very high stability of $\mathrm{CO}_{2}$ and $\mathrm{CH}_{4}$ molecules, it is impossible to convert them directly into liquid products in one-step catalysis. In this context NTP offers a unique way to enable thermodynamically unfavorable chemical reactions at low temperatures owing to the non-equilibrium character of plasma. Non-thermal plasma is created by applying electricity to a gas. The electrons are heated by the electric field applied, and they can activate $\mathrm{CH}_{4}$ molecules by excitation, ionization, and dissociation, creating the reactive species and allowing chemical reactions to occur at near ambient temperature and pressure. While non-thermal plasma is already applied on an industrial scale in waste incineration and ozone manufacturing, its use in $\mathrm{CH}_{4}$ activation to obtain fuels and chemicals, is limited to the laboratory scale. Currently, NTP is seen as an enabling technology for the future of sustainable energy, where chemical processes will be based on renewable sources rather than on fossil fuels [37].

The first application of NTP for DRM reaction was reported by Capezzuto et al. [38]. They used a radiofrequency (RF) plasma reactor to conduct the reaction under a low pressure of 20 Torr and observed that acetylene was the main reaction product. However, low-pressure plasma is not economical for industrial applications due to the high costs of vacuuming and low flow rates. Therefore, subsequent studies were focused on atmospheric-pressure DRM via gliding arc (GA) discharge. The GA plasma produced a mixture of $\mathrm{C}_{2} \mathrm{H}_{2}, \mathrm{C}_{2} \mathrm{H}_{4}, \mathrm{CO}$ and $\mathrm{H}_{2}$ [39]. In atmospheric pressure plasma DRM process, 
the energy for electronic ionization is very high, therefore the overall efficiency strongly depends on the possibility of secondary electron formation in the electron collision step.

Another type of reactors studied is a corona discharge [40]. The discharge can be induced between two symmetric or asymmetric electrodes via AC (for symmetric) or DC (for both cases) power supply and it was also applied for methane activation [41]. Acetylene was the major by-product, and selectivity to $\mathrm{CO}$ was typically higher than to $\mathrm{H}_{2}$ indicating that hydrocarbon formation plays an important role in the corona discharge process [42-45].

The dielectric barrier discharge (DBD) plasma reactor was first reported by Siemens et al. to generate ozone [46]. In this reactor, there is a dielectric layer between the two electrodes. High selectivity to hydrocarbons was attributed to the partial dissociation of $\mathrm{CH}_{4}$ that gives large amounts of $\mathrm{CH}_{\mathrm{x}}$ radicals $(x=1-3)$, which further recombine to form $\mathrm{C}_{2} \mathrm{H}_{6}$ and $\mathrm{C}_{2} \mathrm{H}_{4}$ [12]. A possibility of one-step NTP reforming of $\mathrm{CO}_{2}$ and $\mathrm{CH}_{4}$ into liquid fuels and chemicals was considered to replace the indirect route which normally requires at least two steps. The first step is to produce syngas $\left(\mathrm{CO}\right.$ and $\left.\mathrm{H}_{2}\right)$ which is very similar to thermal methane activation described in Section 1 This is followed by the conversion of syngas into oxygenates in a downstream reactor over platinum group metal (PGM) catalysts (Scheme 1) [10].

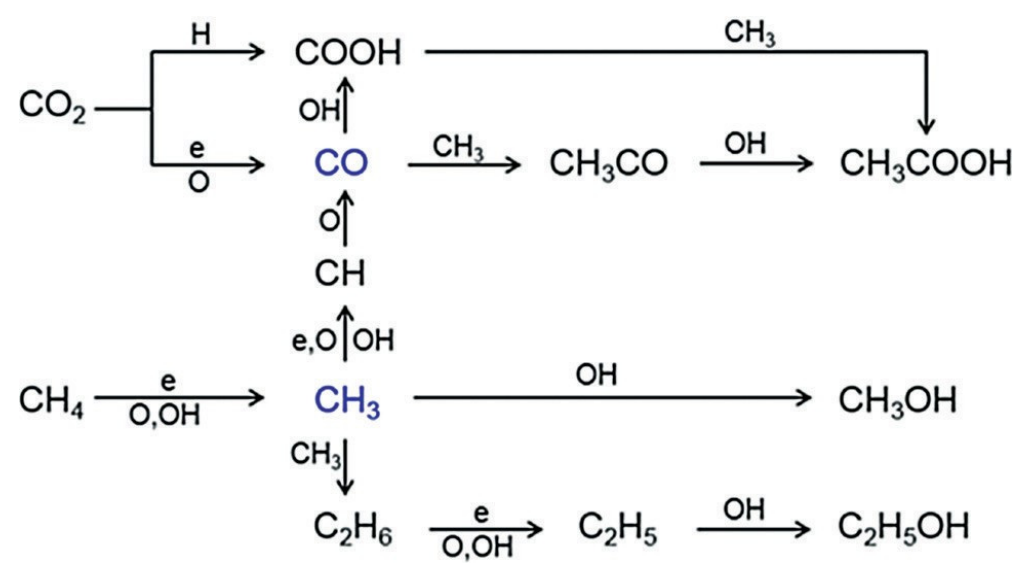

Scheme 1. Possible reaction pathways for the formation of oxygenated liquid products in a dielectric barrier discharge (DBD) reactor (adopted from [10] with permission of Wiley).

\subsection{Dissociation Mechanisms in Different Plasma Reactors}

During the discharge, the electrons with a relatively high kinetic energy of about $10 \mathrm{eV}$ form microfilaments. While this energy is considerably higher than in other non-thermal plasmas, its major part dissipates via the dielectric layer resulting in low energy efficiency $[11,47,48]$. In atmospheric-pressure plasma, the density of electrons with high kinetic energy is relatively low to induce direct dissociation of $\mathrm{CH}_{4}$ and $\mathrm{CO}_{2}$, requiring 9 and $11 \mathrm{eV}$, respectively $[49,50]$. The dissociation of both $\mathrm{CH}_{4}$ and $\mathrm{CO}_{2}$ occurs, therefore, stepwise (Equations (7)-(12)). When vibrational levels of $\mathrm{CO}_{2}$ molecules are excited by plasma, the kinetic energy of electron impact dissociation reduces to from 11 to $5.5 \mathrm{eV}$ [41]. Therefore, excitation of $\mathrm{CO}_{2}$ vibrational level to induce dissociation is an important activation channel in plasma. Several electron impact channels (Equations (8)-(10) and (12)) result in $\mathrm{CO}_{2}$ dissociation [50-52]. During an electron impact excitation, several excited states of $\mathrm{CO}_{2}$ are generated (Equations (7) and (11)) [52].

$$
\begin{gathered}
e+\mathrm{CO}_{2}\left(\mathrm{X}^{1} \sum_{g}^{+}\right) \rightarrow e+\mathrm{CO}_{2}\left(1^{1} \sum_{g}^{+}\right) \\
e+\mathrm{CO}_{2}\left(1^{1} \sum_{u}^{+}\right) \rightarrow e+\mathrm{CO}\left(X^{1} \sum^{+}\right)+O\left({ }^{1} S\right)
\end{gathered}
$$




$$
\begin{gathered}
e+\mathrm{CO}_{2}\left(\mathrm{X}^{1} \sum_{g}^{+}\right) \rightarrow e+\mathrm{CO}\left(a^{3} \prod\right)+\mathrm{O}\left({ }^{5} S\right) \\
e+\mathrm{CO}_{2}\left(\mathrm{X}^{1} \sum_{g}^{+}\right) \rightarrow e+\mathrm{CO}\left(a^{3} \prod\right)+O\left({ }^{5} S\right) \\
e+\mathrm{CO}_{2}\left(X^{1} \sum_{g}^{+}\right) \rightarrow e+\mathrm{CO}_{2}(001) \\
e+\mathrm{CO}_{2}(001) \rightarrow e+\mathrm{CO}\left(X^{1} \sum^{+}\right)+O\left({ }^{1} S\right)
\end{gathered}
$$

Direct electron impact dissociation proceeds through a dissociative electronically excited state. On the contrary, vibrational excitation requires significantly less energy. Once the lowest vibrational levels are populated, they can gradually populate the higher vibrational levels by vibrational-vibrational (VV) collisions. This process, so-called "ladder-climbing" requires the minimum amount of $5.5 \mathrm{eV}$ for $\mathrm{CO}_{2}$ dissociation, providing a more efficient dissociation pathway. The process can be exploited in MW and GA reactors at either reduced pressure or during pulsed plasma operation. This can considerably improve the EE in these plasma types. However, the vibrationally excited species lose their energy upon collision with ground-state molecules. The latter process is called vibrational-translational (VT) relaxation. It depopulates the vibrational levels, and therefore detrimental for energy-efficient conversion by the ladder-climbing pathway. The VT process heats up the gas, while its rate increases with temperature, creating a positive feedback mechanism, which is difficult to control. VT relaxation appears to be quite important in GA plasmas, explaining their high gas temperature (often $3000 \mathrm{~K}$ and above). For this reason, GA plasma is also called "warm plasmas," as its temperature is in between those of NTP such as DBD, which operate typically at room temperature, and thermal plasmas, where the gas temperature can reach $10,000 \mathrm{~K}$, which is the same as the electron temperature. In GA plasma reactors, the electron temperature is higher than the gas temperature, however, the vibrational and gas temperature are close to each other (i.e., vibrational-translational equilibrium is achieved).

\subsection{Configurations of Plasma Reactors}

While the performance of various plasma types is already competitive with other emerging technologies such as electrochemistry, plasma-assisted $\mathrm{CH}_{4}\left(\mathrm{and} / \mathrm{or} \mathrm{CO}_{2}\right)$ conversion is carried out at the laboratory scale and is not implemented in industrial processes. Different types of plasma reactors are being investigated for DRM, including dielectric barrier discharge, microwave, gliding arc plasmas, glow discharges, nanosecond pulsed discharges, corona and spark discharges. They differ in the way the electricity is applied and the value of the electric field, reactor configuration, operation pressure and power. Various reactor designs are briefly summarized in Table 2. 
Table 2. Examples of plasma reactors applied in the DRM reaction and related experimental conditions.

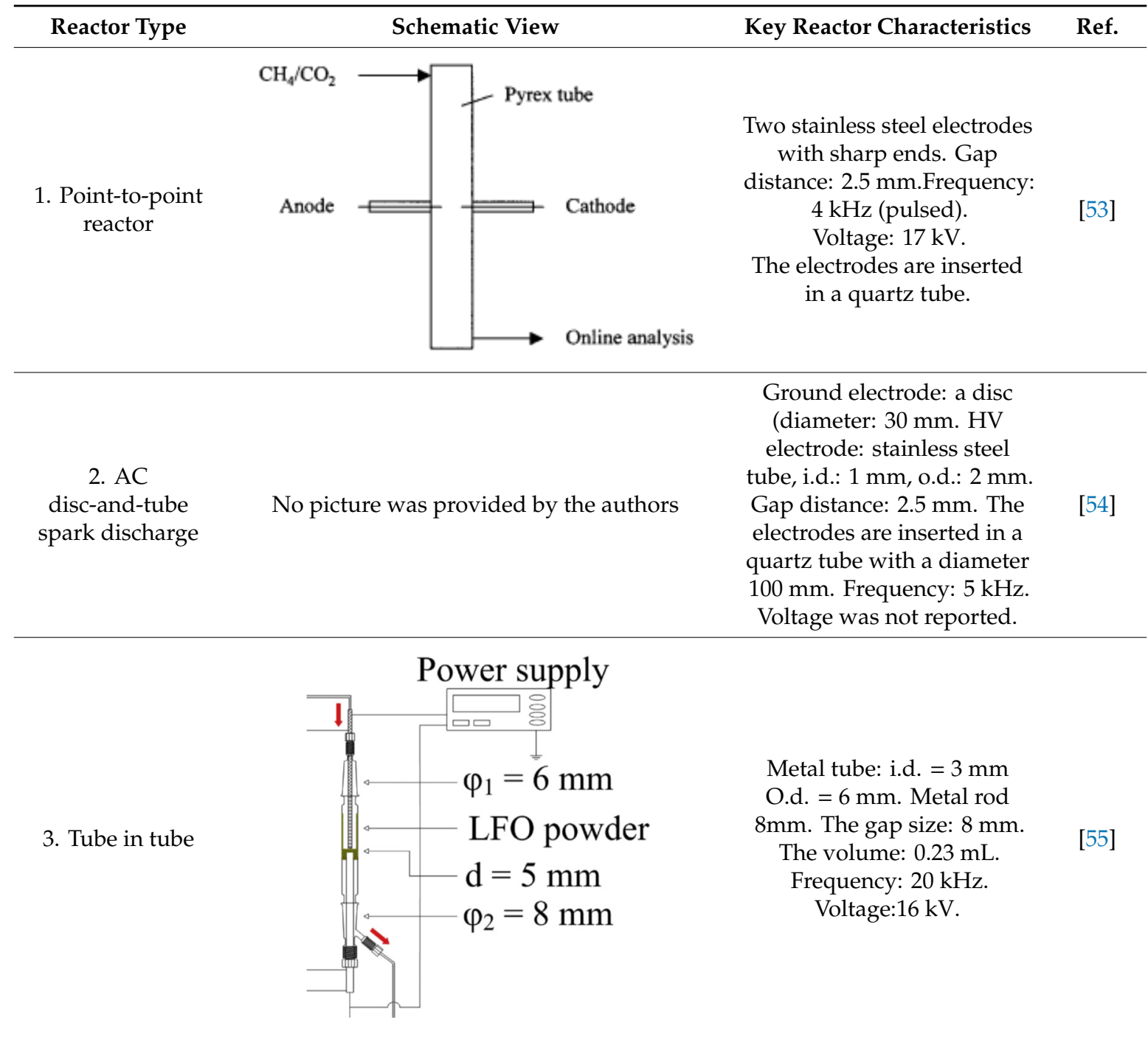

4. Tube in tube
with a
ferroelectric layer


Table 2. Cont.

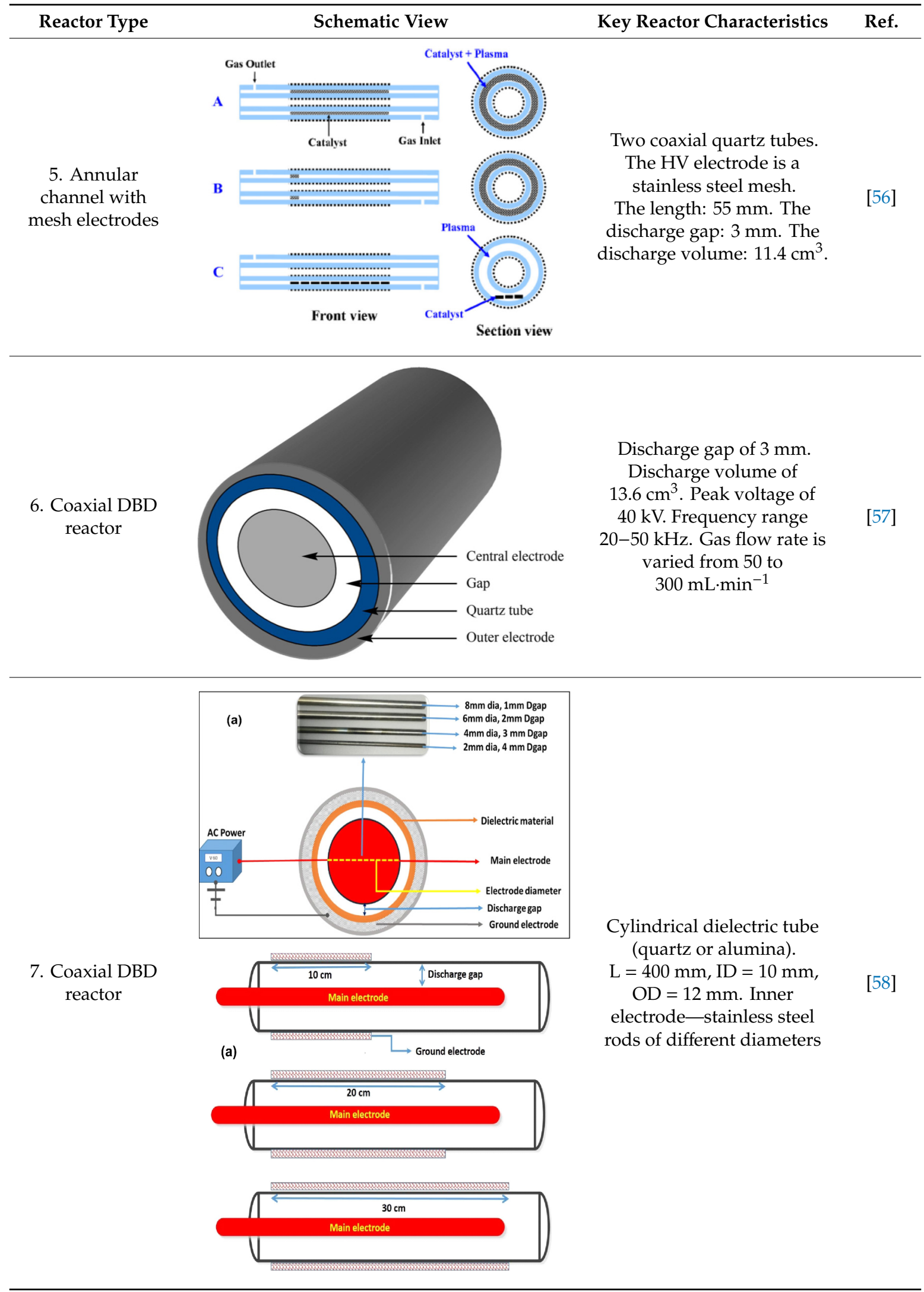


Table 2. Cont.

\begin{tabular}{l}
\hline Reactor Type \\
$\begin{array}{l}\text { 8. AC GA plasma } \\
\text { 9. Reactor with } \\
\text { central and } \\
\text { diffuser-like } \\
\text { electrodes }\end{array}$ \\
$\begin{array}{l}\text { [inker } \\
\text { Externalelectrode }\end{array}$
\end{tabular}

A point-to-point reactor was made of the Pyrex tube $(12 \mathrm{~mm}$ i.d., $15 \mathrm{~mm}$ o.d, $80 \mathrm{~cm}$ length) and two stainless steel sharp electrodes, positioned on the opposite ends of the tube [53]. The voltage was fixed at $17 \mathrm{kV}$. A CO $2 / \mathrm{CH}_{4}$ mixture was fed at a flow rate of $200 \mathrm{~mL} / \mathrm{min}$ at a 1 bar pressure [53]. A spark discharge reactor [54] consisted of a rotary stainless steel disc ( $30 \mathrm{~mm}$ o.d, $3 \mathrm{~mm}$ thickness) as the ground electrode and a stainless steel tube (1 $\mathrm{mm}$ i.d., $2 \mathrm{~mm}$ o.d.) as a high-voltage electrode. The electrodes were placed in a quartz tube $(100 \mathrm{~mm}$ o.d.) at a distance of $6 \mathrm{~mm}$. The reactor operated at an AC voltage of $5 \mathrm{kHz}$. The gas was fed via the tubular electrode. A spark discharge reactor was made of a quartz tube (o.d. $24 \mathrm{~mm}, 36 \mathrm{~cm}$ length) [55]. One electrode was the stainless steel tube ( $3 \mathrm{~mm}$ i.d., $6 \mathrm{~mm}$ o.d.), while the other electrode was a stainless steel rod $(8 \mathrm{~mm} \mathrm{o.d})$ positioned at a distance of $8 \mathrm{~mm}$. A CH $4 / \mathrm{CO}_{2}$ mixture with a molar ratio of 2 was fed at a flow rate of $100-200 \mathrm{~mL} / \mathrm{min}$. A quartz holder was positioned inside the tube to accommodate a catalyst $(2 \mathrm{~g})$. A DC pulse operation at $16 \mathrm{kV}$ with a pulse rising time between 25 and $100 \mu$ s was studied. In a similar configuration presented in [12]. A BZT ferroelectric layer $(0.5 \mathrm{~g})$ was positioned between the two electrodes positioned at a distance of $5 \mathrm{~mm}$ from each other. The reactor operated at DC pulses of $20 \mathrm{kV}$. A GHSV has varied in the range of $8500-85,000 \mathrm{~h}^{-1}$. A DBD reactor with an annular channel with mesh electrodes was demonstrated in [56]. The reactor consists of two coaxial quartz tubes covered with stainless steel mesh electrodes. The high voltage electrode was positioned in the center, and the outer electrode was grounded. The length of the discharge region was $55 \mathrm{~mm}$ with a discharge gap of $3 \mathrm{~mm}$. A CH $4 / \mathrm{CO}_{2}$ mixture with a molar ratio of 1 was fed at a flow rate of $25-100 \mathrm{~mL} / \mathrm{min}$. The reactor operated at a peak-to-peak voltage of $24 \mathrm{kV}$ and a variable frequency of $30-40 \mathrm{kHz}$. A different design of a coaxial DBD reactor was presented in [57]. In this reactor, the center electrode was grounded while the outer electrode was connected to an AC high voltage output $(40 \mathrm{kV})$. The discharge region was $90 \mathrm{~mm}$. The reactant flow rate was $50-300 \mathrm{~mL} / \mathrm{min}$. The electrodes were cooled with water. A cylindrical dielectric tube (10 $\mathrm{mm}$ i.d, $40 \mathrm{~cm}$ length) with an aluminum mesh was used in a coaxial DBD reactor in [58]. A stainless steel rod was used as the center electrode. 
An AC gliding arc plasma reactor operating at $10 \mathrm{kV}$ was demonstrated in [59]. Two semiellipsoidal aluminum electrodes (50 $\mathrm{mm}$ long, $30 \mathrm{~mm}$ wide) were fixed in an insulating housing and symmetrically placed on both sides of a gas nozzle with a diameter of $1.5 \mathrm{~mm}$. A 3D cylindrical tornado electrode (3D-CTE) with the shape of the conical diffuser ( $2 \mathrm{~mm}$ o.d.) provided higher efficiency for interactions between the plasma species and the reactants [60]. A needle electrode was placed in the middle of the reactor. The gap between the tip of the needle electrode and the throat was $0.6 \mathrm{~mm}$. The plasma was created with an AC power supply operated at $4-8 \mathrm{kV}$ at a frequency of $50 \mathrm{~Hz}$.

It can be concluded that the three most common plasma types are DBD, spark, and GA plasma reactors. The two electrodes can be parallel plates, but for $\mathrm{CH}_{4}$ conversion, a cylindrical configuration in which the two electrodes are concentric cylinders, is desirable as it minimizes the amount of gas bypassing the plasma zone. DBD reactors have a rather simple design, which makes it easy for upscaling and industrial applications. In addition, the simple design allows the implementation of catalysts and ferroelectric materials inside the reactors in order to improve the selectivity towards high added value chemicals and reaction rate.

In a GA plasma reactor, an electric potential difference is applied between two flat diverging electrodes. An arc is created at the shortest distance near the gas inlet, and it glides towards the reactor outlet carried by gas flow until it extinguishes. Then a new arc is created again at the shortest distance and the process continues. A GA reactor operates at atmospheric pressure, and exhibits quite good energy efficiency.

A spark plasma arises when applying electric power between two point electrodes in the space filled with gas. The gas temperature can easily rise to above $4000 \mathrm{~K}$ which makes the application of catalysts possible only in post-plasma mode (as it will be discussed in the next sections).

\section{Characteristics of Plasma Reactors}

\subsection{Main Efficiency Parameters}

The energy efficiency (EE) is defined as the total syngas generated per kilowatt-hour input (Equation (13)) to compare the syngas generation efficiency for different plasma reactors [61]:

$$
E E\left(\frac{\mathrm{mol}}{\mathrm{kWh}}\right)=\frac{n_{\mathrm{H}_{2}}+n_{\mathrm{CO}}}{t P}=\frac{3.6}{P} \frac{F_{V}}{R T} p,
$$

where $n$ is the number of products, $P$ is the electric power, $\mathrm{t}$ is discharge time, $p$ is the pressure, $F_{V}$ is the volumetric flow rate, $T$ is the temperature, and $R$ is the ideal gas constant. The EE can also be expressed in grams of $\mathrm{H}_{2}$ per $\mathrm{kWh}$ or \%. Expressing EE in percentage is a common method to estimate chemical energy efficiency based on the reactant conversion, total power supplied to the system and the heat of the target DRM reaction [61]:

$$
E E(\%)=\frac{\left(n \mathrm{CH}_{4}\right)_{\text {converted }} \times \Delta H_{298}}{P}
$$

where $\Delta H_{298}=247 \mathrm{~kJ} / \mathrm{mol}$.

An EE research target of $60 \%$ was defined by Snoeckx and Bogaerts [62] based on the comparison with electrochemical water splitting, being the main competitor of plasma conversion for storing renewable energy, and already reaching commercial energy efficiencies of $65-75 \%$. A comparison with other novel technologies for $\mathrm{CO}_{2}$ conversion, which directly use solar energy (solar thermochemical conversion with a solar-to-fuel conversion efficiency of $20 \%$ ) requires a plasma-based $\mathrm{CO}_{2}$ conversion with an EE of $60-80 \%$ to get an overall solar-to-fuel efficiency of $15-20 \%$. 
Another useful parameter, the specific energy density (SED), is defined as the average power dissipated in the discharge divided by the total gas flow rate. The discharge power $(P)$ is calculated by the effective voltage $(U)$ multiplied by the current $(I)$ (Equation15):

$$
\operatorname{SED}\left(\frac{J}{L}\right)=\frac{P}{F_{V}}=\frac{U_{\max } I}{\sqrt{2} F_{V}}
$$

It can be seen that the SED is a reciprocal function of $E E$, expressed in different units: Liter instead of mol and Joule instead of $\mathrm{kWh}$. Increasing the flow rate usually results in higher $E E$ in warm plasma types (corona, GA, spark) because of more chance for impact dissociations utilizing high energy electrons (Figure 1). However, the too-high flow rate decreases the $E E$ because the secondary electron production is decreased. Selectivity to $\mathrm{H}_{2}$ and $\mathrm{CO}$ is almost independent of the flow rate [41].

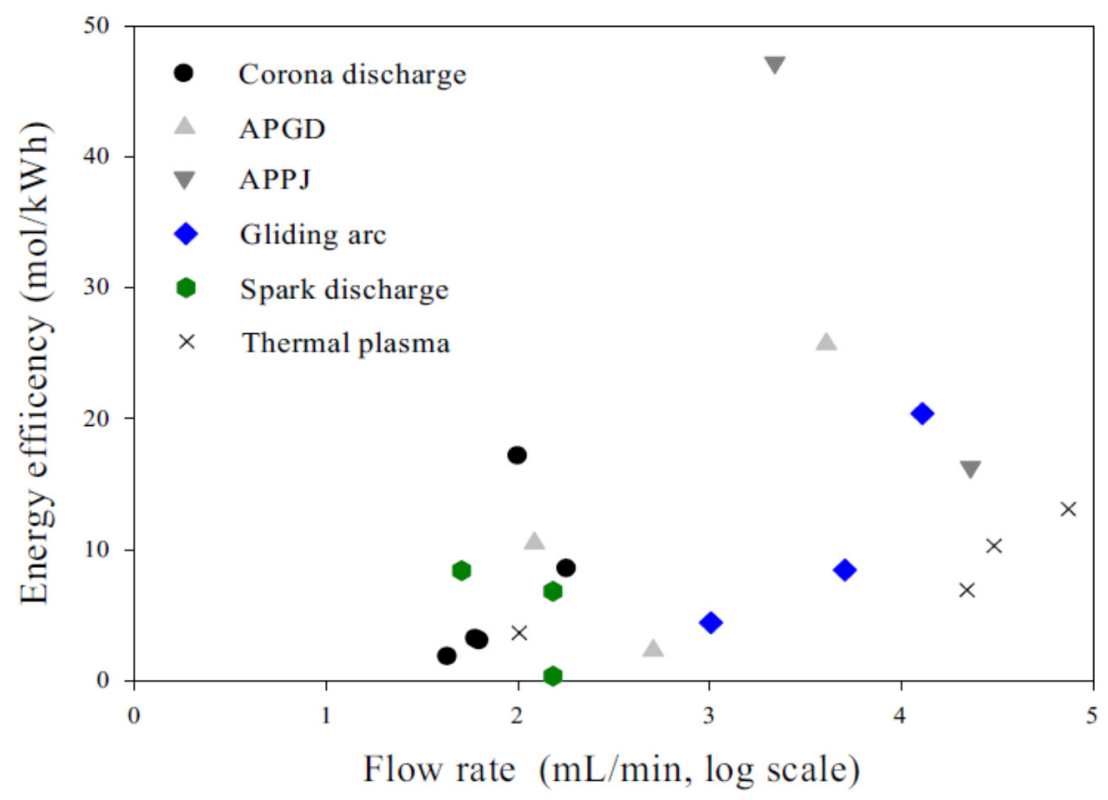

Figure 1. The energy efficiency (EE) as a function of flow rate in warm plasma. Reproduced with permission from [41]. Copyright 2020, Elsevier.

The local electric field near the contact point between the pellets can be 10-10 that in a spherical void. The average electric field $(E)$ inside a spherical void and the corresponding electron density (number of electrons in the reactor volume, $n_{\mathrm{e}}$ ) are expressed by Equations (16) and (17), respectively [63].

$$
\begin{gathered}
E \approx \frac{V}{d} \frac{3 \varepsilon_{p}}{2 \varepsilon_{p}+\varepsilon_{g}} \\
n_{e} \approx \frac{P}{V \alpha A e \mu_{0} E_{0}^{\omega} E^{1-\omega}} \approx \frac{P}{V \alpha A e \mu_{0} E_{0}^{\omega}\left(\frac{V}{d} \frac{3 \varepsilon_{p}}{2 \varepsilon_{p}+\varepsilon_{g}}\right)^{1-\omega}},
\end{gathered}
$$

where $V$ is the voltage, $d$ is the gap size between the electrodes, $\varepsilon_{\mathrm{g}}$ and $\varepsilon_{\mathrm{p}}$ are the dielectric constants of the background gas and the pellets, respectively, $\alpha$ and $A$ are the void fraction and cross-sectional area of the reactor, respectively, $e$ is the electric charge of electrons $\left(e=1.6 \times 10^{-19} \mathrm{C}\right), \mu_{0}$ is the electron mobility at the reference electric field $E_{0}$, and $\omega$ is an empirical coefficient, which depends on the gas properties. For example, $\omega$ is equal to 0.501 and 0.198 for air and nitrogen, respectively [64]. It can be seen from Equation (16), that the electric field has a minimum value $\left(E_{x} \approx V / d\right)$ when $\varepsilon_{g} \approx \varepsilon_{p} \approx 1$.

The gamma value, being the normalized capacitance $\gamma=\left(\mathrm{C}_{\text {diel }}-\zeta_{\text {diel }}\right) /\left(\mathrm{C}_{\text {diel }}-\mathrm{C}_{\text {cell }}\right)$, where $\mathrm{C}_{\text {diel }}$ and $C_{\text {cell }}$ are the electrical capacitances of the reactor, defined from its geometry, $\zeta_{\text {diel }}$ is an effective capacitance, represents the areal fraction of the electrodes that is not discharging. A value of zero 
$(\gamma=0)$ indicates complete charge bridging in the reactor, and a value of $\gamma=1$ indicating no charge bridging (i.e., no plasma present). With increasing voltages, the gamma value generally tends to decrease from 1 to 0 at the highest applied voltages [65]. This rapid decrease in gamma is due to a charge being transferred across the gap, rather than being 'trapped' by the pellet. In a packed bed reactor, each packing pellet acts as an individual capacitor and can therefore trap charges.

\subsection{The Effect of Reduced Electric Field on the DRM Reactor Choice}

The influence of the reduced electric field $\mathrm{E} / \mathrm{n}\left(\mathrm{Td}=\right.$ Townsend, $\left.1 \mathrm{Td}=10^{-21} \mathrm{~V} \cdot \mathrm{m}^{2}\right)$ on the electron energy loss deposited into relevant excitation, dissociation, or ionization channels of $\mathrm{N}_{2}$ and $\mathrm{CO}_{2}$ in reactors is shown in Figure 2 [66]. As an example, in a nitrogen plasma, a reduced electric field of $100 \mathrm{Td}$ corresponds to average electron energy of approximately $2 \mathrm{eV}$. It can be seen from Figure 2 that a significant fraction of the energy is converted into the internal energy of rotational and vibrational excitations at low electric fields, while the higher-energy electronic excitation, ionization, and dissociation channels become significant at reduced electric fields of $100 \mathrm{Td}$ or above. It is worth to mention that the level of $100 \mathrm{Td}$ corresponds to a DBD regime (dashed vertical lines in Figure 2 indicate $\mathrm{E} / \mathrm{n}$ values demarking the onset of the DBD regime). It can be seen that the efficiency of vibrational excitations is close to zero in a DBD regime, whereas the electronic excitation has a maximum at $200 \mathrm{Td}$. This explains the low values of $E E$ as listed in Table 3.

Table 3. Comparison of dry reforming of methane assisted by different methods.

\begin{tabular}{|c|c|c|c|c|c|c|c|c|c|c|}
\hline \multirow{2}{*}{$\begin{array}{l}\text { Plasma } \\
\text { Type }\end{array}$} & \multirow{2}{*}{$\begin{array}{c}\text { Reactor } \\
\text { Type }\end{array}$} & \multirow{2}{*}{$\begin{array}{l}\text { Packing } \\
\text { Material }\end{array}$} & \multirow{2}{*}{ Reaction Conditions } & \multirow{2}{*}{$\begin{array}{l}\text { SED } \\
{[\mathrm{J} / \mathrm{mL}]}\end{array}$} & \multicolumn{2}{|c|}{ Conversion (\%) } & \multicolumn{2}{|c|}{ Selectivity (\%) } & \multirow{2}{*}{$\begin{array}{c}\mathrm{EE} \\
(\mathrm{mol} / \mathrm{kWh})\end{array}$} & \multirow{2}{*}{ Ref. } \\
\hline & & & & & $\mathrm{CH}_{4}$ & $\mathrm{CO}_{2}$ & $\mathrm{H}_{2}$ & $\mathrm{CO}$ & & \\
\hline DBD & $\begin{array}{l}\text { Annular } \\
\text { channel }\end{array}$ & $\mathrm{Ni} / \gamma-\mathrm{Al}_{2} \mathrm{O}_{3}$ & $\begin{array}{c}1_{\text {gap }}=3 \mathrm{~mm}, \\
\mathrm{Q}=50 \mathrm{~mL} / \mathrm{min} \\
30-40 \mathrm{kHz}, 24 \mathrm{kV} \\
8 \mathrm{kV} / \mathrm{mm}, 50 \mathrm{~W}\end{array}$ & 60.0 & 38.0 & 21.0 & 28.0 & 45.0 & 1.17 & [56] \\
\hline Spark & & - & $\mathrm{Q}=150 \mathrm{~mL} / \mathrm{min}, 45 \mathrm{~W}$ & 18.0 & 65.0 & 55.0 & 62.0 & 87.0 & 6.61 & [54] \\
\hline RF & & - & $\mathrm{Q}=200 \mathrm{~mL} / \mathrm{min}, 36.2 \mathrm{~W}$ & 10.9 & 65.9 & 57.8 & & 85.9 & 8.64 & [53] \\
\hline GA & $2 \mathrm{D}$ & - & $\begin{array}{c}l_{\text {gap }}=3.2 \mathrm{~mm} \\
\mathrm{Q}=7500 \mathrm{~mL} / \mathrm{min} \\
0.05 \mathrm{kHz}, 24 \mathrm{kV} \\
6.25 \mathrm{kV} / \mathrm{mm}, 165 \mathrm{~W}\end{array}$ & 1.3 & 13.1 & 8.4 & 31.4 & 69.5 & 11.16 & [56] \\
\hline Spark & $\begin{array}{l}\text { Tube in } \\
\text { tube }\end{array}$ & C-BZT ${ }^{1}$ & $\begin{array}{c}1_{\text {gap }}=5 \mathrm{~mm}, \\
\mathrm{Q}=200 \mathrm{~mL} / \mathrm{min}, \\
22 \mathrm{kHz}, 24 \mathrm{kV}, \\
3.6 \mathrm{kV} / \mathrm{mm}, 39.3 \mathrm{~W}\end{array}$ & 11.8 & 86.9 & 83.3 & 90.1 & 66.0 & 16.53 & [12] \\
\hline Spark & $\begin{array}{l}\text { Tube in } \\
\text { tube }\end{array}$ & - & $\begin{array}{c}l_{\text {gap }}=8 \mathrm{~mm}, \\
\mathrm{Q}=350 \mathrm{~mL} / \mathrm{min}, \\
20 \mathrm{kHz}, 24 \mathrm{kV} \\
2 \mathrm{kV} / \mathrm{mm}, 41.4 \mathrm{~W}\end{array}$ & 7.1 & 42.3 & 30.2 & 76.9 & 67.1 & 14.38 & [55] \\
\hline Spark & $\begin{array}{c}\text { Tube in } \\
\text { tube }\end{array}$ & $\mathrm{LFO} 600^{2}$ & $\begin{array}{c}l_{\text {gap }}=8 \mathrm{~mm}, \\
\mathrm{Q}=350 \mathrm{~mL} / \mathrm{min}, \\
20 \mathrm{kHz}, 24 \mathrm{kV} \\
2 \mathrm{kV} / \mathrm{mm}, 44.6 \mathrm{~W}\end{array}$ & 7.6 & 53.5 & 40.0 & 85.0 & 71.8 & 18.42 & [55] \\
\hline
\end{tabular}

${ }^{1} \mathrm{C}-\mathrm{BZT}$ - coarse $\mathrm{BaZr}_{0.05} \mathrm{Ti}_{0.95} \mathrm{O}_{3}$ particles of size of $210-420 \mu \mathrm{m}$ )—ferroelectric material. ${ }^{2} \mathrm{LFO} 600$-perovskite-type photocatalyst, $\mathrm{LaFeO}_{3}$. notations: $\mathrm{l}_{\mathrm{g}}$ —gap length $[\mathrm{mm}] ; \mathrm{Q}$-gas flowrate $[\mathrm{ml} / \mathrm{min}]$; Input voltage in $[\mathrm{kV}]$, frequency in $[\mathrm{kHz}]$, power in $[\mathrm{W}]$ and electric field in $[\mathrm{kV} / \mathrm{mm}]$.

It can be seen in Figure 2, a reduced electric field of about $50 \mathrm{Td}$ is ideal for vibration-induced dissociation. This value is typically observed in the microwave and GA plasma reactors, which explains their high EE. However, DBD reactors operate in the higher $\mathrm{E} / \mathrm{n}$ range. Therefore, it is necessary to lower the reduced electric field in DBD reactors to values below $100 \mathrm{Td}$. In theory, this can be done in two ways: (i) by lowering the applied electric field (E) or (ii) by increasing the number of electrons in the reactor volume $(n)$. The applied electric field is determined by the power source. As such applying lower power may be beneficial, although the power should be sufficient to create a stable plasma. However, this approach would not always create a lower electric field, as the $\mathrm{CH}_{4}$ DBD plasma is typically filamentary. Therefore, lower power may also create fewer filaments instead of a lower 
electric field in these filaments. Thus, it is not straightforward to control the $\mathrm{E} / \mathrm{n}$ value in a DBD plasma reactor [67].
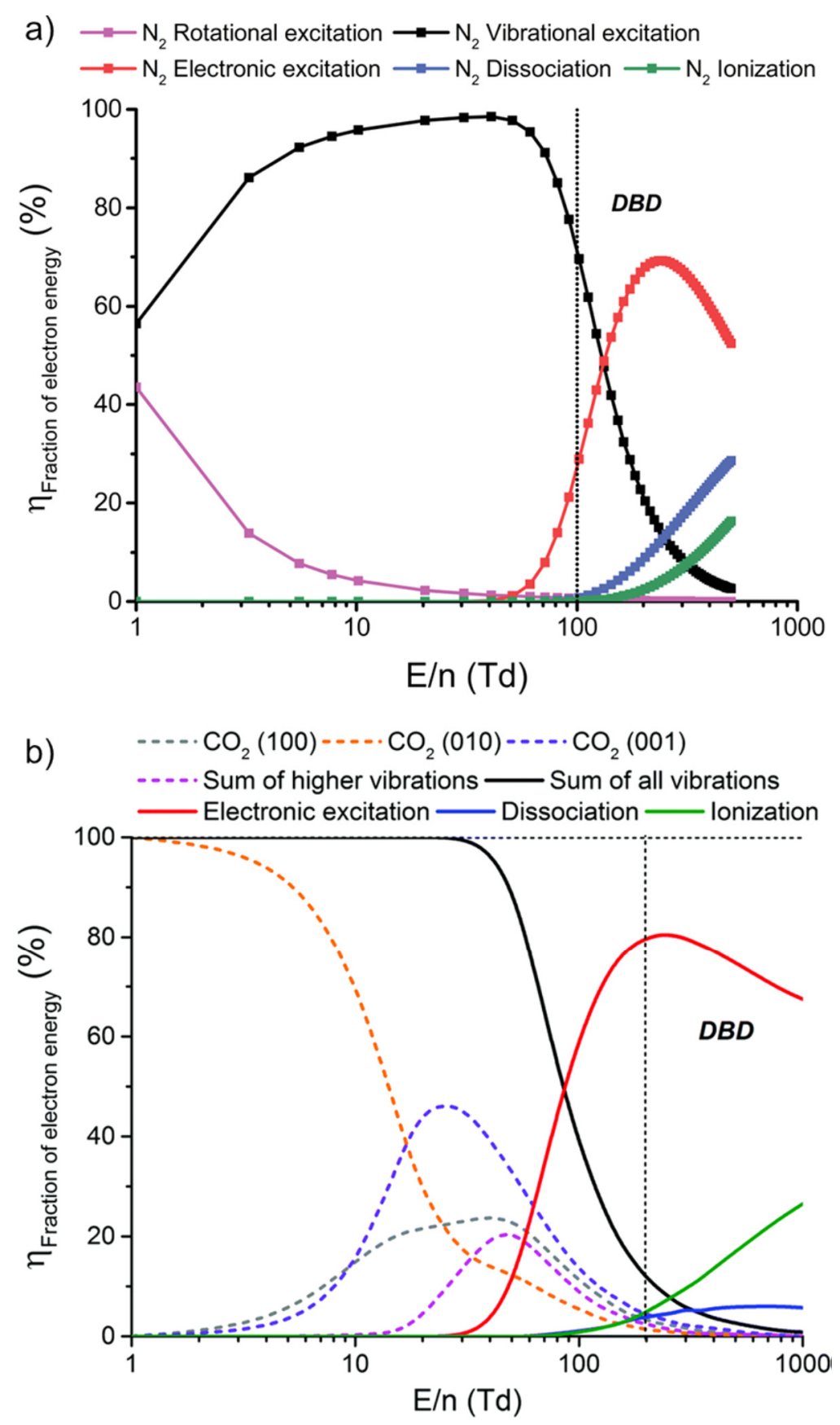

Figure 2. Electron energy loss channels in (a) $\mathrm{N}_{2}$ plasmas and (b) $\mathrm{CO}_{2}$ plasmas as a function of the reduced electric field. The vertical dashed line indicates the start of the DBD regime (Reproduced with permission from [66]. Copyright 2020, ACS).

The microwave (MW) plasma is seldom employed in the DRM reaction (Table 4). Hrycak et al. [68] conducted experiments with microwave pulsed plasma for syngas production using a mixture of $\mathrm{CH}_{4}$ and $\mathrm{CO}_{2}$ at a molar ratio of 0.66 . The optimum $\mathrm{H}_{2}$ production rate was $156 \mathrm{~g} / \mathrm{h}$ at a power input of $7.5 \mathrm{~kW}$. An EE of $21 \mathrm{~g} / \mathrm{kWh}(\mathrm{EE}=7.2 \%)$ was reported at a $\mathrm{CH}_{4}$ conversion of $80 \%$. The highest yield of $43 \mathrm{~g}\left(\mathrm{H}_{2}\right) / \mathrm{kWh}$ was reported when water vapor was fed in the plasma region [69]. The performance was enhanced with the implementation of $\mathrm{C}_{4}$ recycling loop [70]. However, the yield was still 
rather far from the US Department of Energy (DOE) set a target for $\mathrm{H}_{2}$ production of $60 \mathrm{~g} / \mathrm{kWh}$ which is needed for a large scale industrial implementation [71].

Table 4. Microwave plasma reactors employed of DRM [68].

\begin{tabular}{|c|c|c|c|c|}
\hline Production Method & $\begin{array}{c}\text { Initial } \\
\text { Composition } \\
\text { (Molar Ratio) }\end{array}$ & $\begin{array}{l}\mathrm{H}_{2} \text { Production } \\
\text { Rate }\left[\mathrm{g}\left(\mathrm{H}_{2}\right) / \mathrm{h}\right]\end{array}$ & $\begin{array}{c}\mathrm{EE} \\
{\left[\mathrm{g}\left(\mathrm{H}_{2}\right) / \mathrm{kWh}\right]}\end{array}$ & $\begin{array}{c}\mathrm{CH}_{4} \text { Conversion } \\
\left(\mathrm{H}_{2} \text { Selectivity }\right) \\
{[\%]}\end{array}$ \\
\hline $\mathrm{CH}_{4}$ steam reforming & $\mathrm{CH}_{4}+\mathrm{H}_{2} \mathrm{O}+\mathrm{Air}$ & large scale & 60 & Benchmark case \\
\hline Corona & $\mathrm{CH}_{4} / \mathrm{CO}_{2}(1.00)$ & 0.46 & 12.6 & $12.627 .8(55.1)$ \\
\hline Glow discharge & $\mathrm{CH}_{4} / \mathrm{CO}_{2}(1.00)$ & 0.28 & 12.2 & $61(77)$ \\
\hline DBD & $\mathrm{CH}_{4} / \mathrm{CO}_{2}(2.33)$ & 0.25 & 5.5 & $11(98)$ \\
\hline DBD & $\mathrm{CH}_{4} / \mathrm{CO}_{2}(1.00)$ & 0.06 & 0.42 & $62(75)$ \\
\hline AC-pulsed arc plasma & $\begin{array}{c}\mathrm{CH}_{4} / \mathrm{CO}_{2}+\mathrm{Air} \\
(1.5+3.3)\end{array}$ & 13.1 & 394 & $80(54)$ \\
\hline Rotating GA & $\mathrm{CH}_{4} / \mathrm{CO}_{2}(0.43)$ & 12.4 & 25.2 & $58.5(35.3)$ \\
\hline $\begin{array}{c}\text { Coaxial-line-based } \\
\text { microwave }(2.45 \mathrm{GHz})\end{array}$ & $\mathrm{CH}_{4} / \mathrm{N}_{2}(2.0)$ & 50 & 14.6 & $40.1(30)$ \\
\hline $\begin{array}{l}\text { Metal-cylinder-based } \\
\text { microwave }(2.45 \mathrm{GHz})\end{array}$ & $\mathrm{CH}_{4} / \mathrm{CO}_{2}(1.0)$ & 66 & 19 & $32.5(40.9)$ \\
\hline $\begin{array}{l}\text { Metal-cylinder-based } \\
\text { microwave }(2.45 \mathrm{GHz})\end{array}$ & $\begin{array}{c}\mathrm{CH}_{4}+\mathrm{CO}_{2}+\mathrm{H}_{2} \mathrm{O} \\
(30: 12: 25)\end{array}$ & 192 & 43 & 22 (n.d) \\
\hline $\begin{array}{l}\text { Quartz-cylinder-based } \\
\text { microwave }(2.45 \mathrm{GHz})\end{array}$ & $\mathrm{CH}_{4}+\mathrm{CO}_{2}(1.00)$ & 112 & 19 & $96.8(77.2)$ \\
\hline $\begin{array}{l}\text { Metal-cylinder-based } \\
\text { microwave (915 MHz) }\end{array}$ & $\mathrm{CH}_{4}+\mathrm{CO}_{2}(0.66)$ & 156 & 21 & $61.4(63.7)$ \\
\hline
\end{tabular}

\section{Dielectric Barrier Discharge Reactors}

Dielectric barrier discharge (DBD) is the most popular type of plasma reactors used for DRM in the past, partly due to its simple design, easy scalability and its affordability for pilot-scale research [72,73]. The conversion and EE depend on the applied power, specific energy input, operating pressure and temperature. Introduction of the inert gas such as helium, argon and nitrogen as well as a catalyst can improve yields of hydrogen and CO (syngas route) and different hydrocarbons [74,75].

\subsection{AC Mode}

Usually, the DBD reactors operate in the so-called filamentary mode when the gas excitation occurs in the discharge volume by stochastically distributed microdischarge channels of $0.1-1 \mathrm{~mm}$ in diameter that appear during each half-period of the applied AC voltage. There is a good understanding of the physical mechanisms involved in the DBD operation. However, the literature lacks kinetic information about some of the individual steps involved. There are also no detailed models of plasma chemical reactors accounting for a complex microdischarge channels structure and convective heat and mass transport by the gas flow.

Snoeckx and Bogaerts [62] summarized recent research data for DRM obtained in DBD reactors for both packed and unpacked configurations. The results are shown in Figure 3 where the energy costs are shown as a function of conversion. It can be seen that the energy cost decreases with an increasing total conversion for the packed DBD reactor on the contrary to the non-packed discharge.

Wang et al. [76] reported a conversion for $\mathrm{CH}_{4}$ (and $\mathrm{CO}_{2}$ ) into syngas of $80 \%$ at the equimolar ratio. The selectivity to hydrogen reached $100 \%$ at a $\mathrm{CH}_{4} / \mathrm{CO}_{2}$ molar ratio of 0.2 . The authors concluded that the multistage ionization was critical for achieving such high conversion. Li et al. [75] also reported a significant improvement in conversion for multistage ionization. They also found a strong correlation between the discharge gap and the selectivity to ethanol and methanol, with a larger discharge gap giving a high concentration of alcohols in the product stream. 

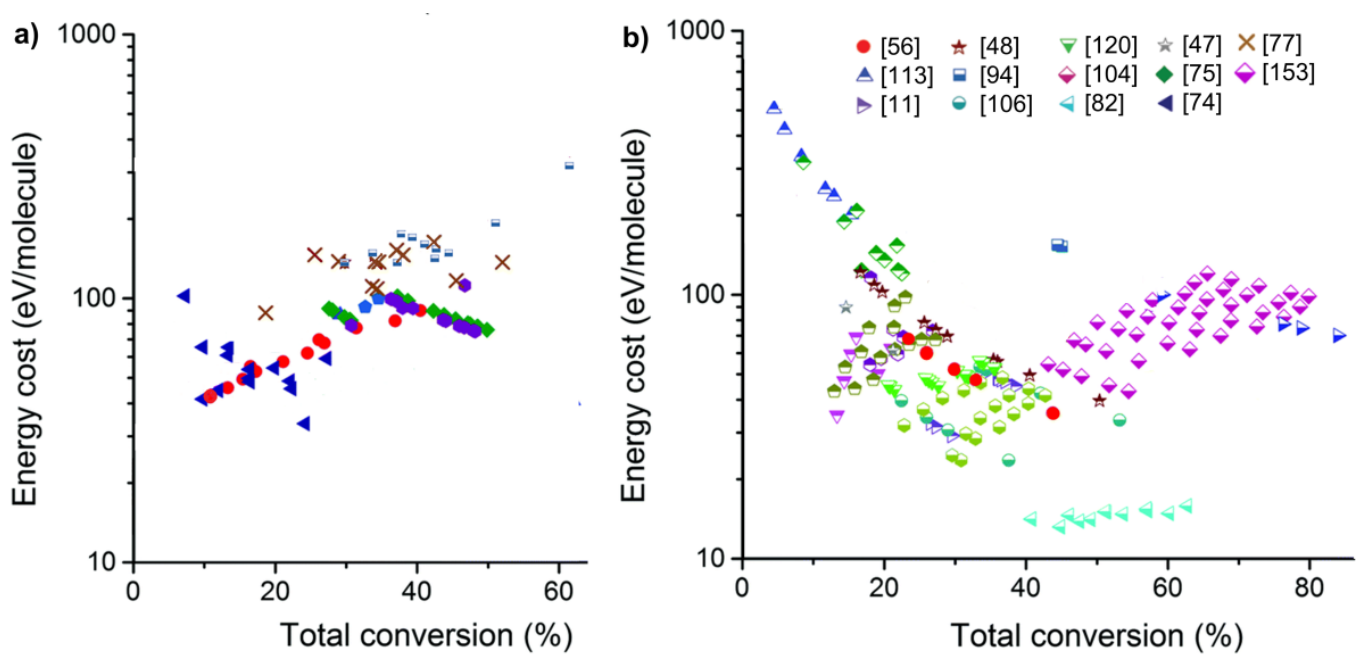

Figure 3. Experimental data collected from literature for direct reforming of methane with carbon dioxide for (a) non packed dielectric barrier discharge (b) packed bed dielectric discharge barrier. Reproduced with permission from [62]. Copyright 2020, RSC.

\subsection{Pulsed Discharge Mode}

More recently nanosecond pulsed discharge (NPD) mode was also studied where the gas volume is excited homogeneously. The discharge volume was divided into plasma elements that are not connected with each other, but contribute to the total resistance of the plasma [72]. Over the last 5 years, it was reported that the shorter pulsed power gives an improvement of energy efficiency, especially in $\mathrm{CO}_{2}$ activation. Therefore, the development of nanosecond pulse discharge reactors (and corresponding generators) is of paramount importance for practical applications. Both chemical and physical effects, influencing also the plasma discharge behavior and electrical properties, were identified. However, the pulse power supply mode is generally associated with a higher equipment price which seems to be the main reason for its relatively low penetration into the research community so far. At equal peak voltage, the AC power supply gives a low current continuously while pulse power source provides a higher current and therefore the power in a moment for a short time ranging from microseconds to nanoseconds [77].

The application of pulsed power instead of continuous AC or DC supply improves methane conversion [77]. Figure 4 shows a considerable improvement in $\mathrm{CH}_{4}$ conversion and the $\mathrm{EE}$ in terms of SED under the pulsed power supply. At lower energy input, the conversion increases from 5 to $40 \%$. However, both the EE and conversion approach those in AC operation at a higher energy input of $6000 \mathrm{~kJ} / \mathrm{mol}$. $\mathrm{CH}_{4}$ conversion of $60 \%$ was reported which is close to the state-of-the-art level in $\mathrm{CH}_{4}$ DBD reactors.

As the pulse width increased from 2 to $5 \mu$ s, the $\mathrm{CH}_{4}$ conversion decreased from 47 to $42 \%$ at the same selectivity. However, shorter pulses further increased energy efficiency [77]. The nanosecond pulse discharge gives a $\mathrm{CH}_{4}$ conversion of $50 \%$ with a $65 \%$ hydrogen selectivity at a SED of $448 \mathrm{~kJ} / \mathrm{mol}$ and a residence time of 12-36 ms [78]. Thus the ultra-short pulses allowed to increase the efficiency of DBD reactor to the level of other types such as GA, spark and corona [78]. Wang et al. determined an optimal pulse peak width of $150 \mathrm{~ns}$ in an empty DBD reactor. Both $\mathrm{CH}_{4}$ and $\mathrm{CO}_{2}$ conversion decreased as pulse rise time increased [79]. Cheng et al. used almost instantaneous power input of $0.8 \times 10^{6} \mathrm{~W}$ (SED: $10 \mathrm{~J} / \mathrm{cm}^{3}$ ) and short pulses (below $1 \mathrm{~ns}$ ) to improve the EE [80]. They developed a numerical model of a packed bed DBD reactor operated under ns-pulse plasma and observed a good agreement between their computational results and the experiments. The simulations showed that the low duty cycle (short plasma on-time) resulted in the low gas temperature and slow recombination kinetics, which improved the $\mathrm{CH}_{4}$ and $\mathrm{CO}_{2}$ conversions. 


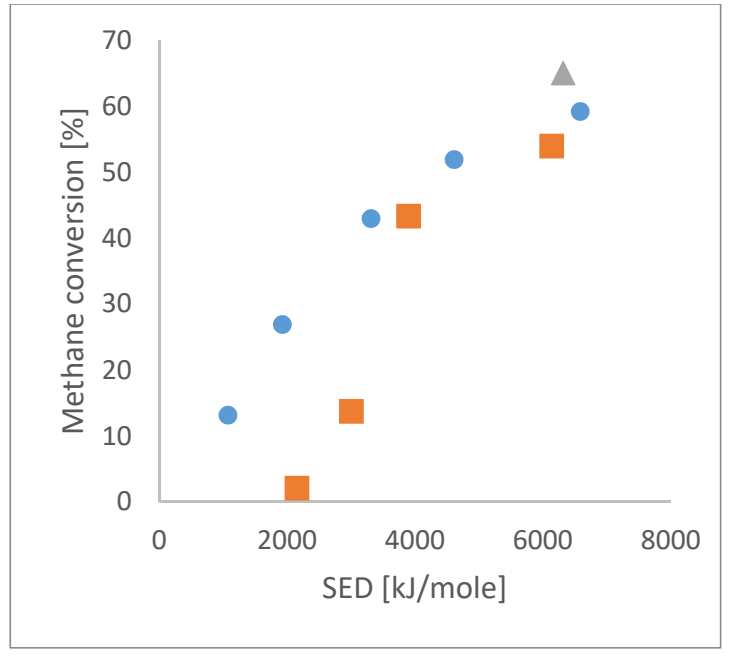

(a)

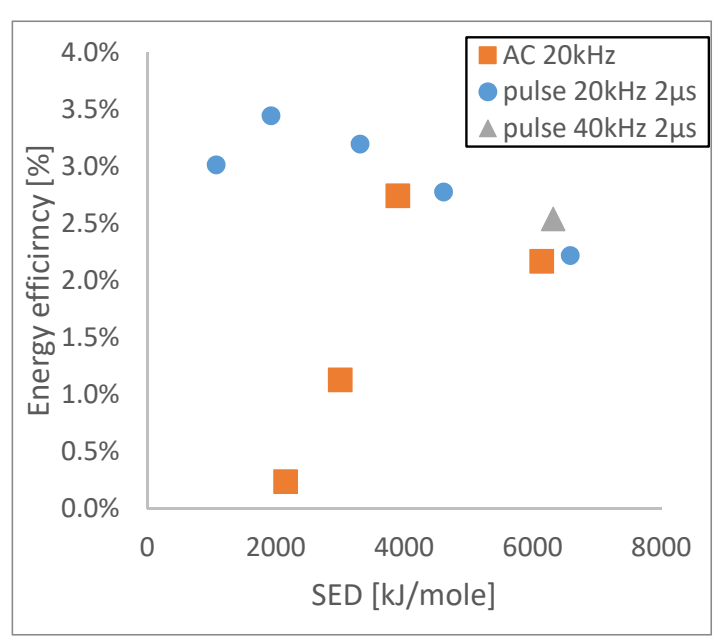

(b)

Figure 4. $\mathrm{CH}_{4}$ conversion (a) and energy efficiencies (b) in AC and power supply for DRM process in DBD reactor without packing (data adopted from [77] and represented as a function of SED).

\section{Effect of Ferroelectric Materials on the Plasma Discharge}

Without discharge, the ferroelectric materials exhibit no polarization and no electrostatic force exists between electrons and ions. With an external electric field, the cations in the ferroelectric are attracted by the external electrostatic force in one direction and the anions $\left(\mathrm{O}^{-2}\right)$ are attracted by the electrostatic force to the opposite direction, resulting in polarization. After polarization, the ferroelectric surfaces have positive and negative charges. While polarization of an insulator disappears with the external electric field is removed, a ferroelectric retains a portion of its polarization, called the remnant polarization, owing to internal forces in its crystalline structure. The positive charge on the surface electrostatically attracts electrons, increasing their kinetic energy. Dielectric constants of typical materials used in plasma reactors are shown in Table 5.

Table 5. Dielectric constant of typical materials.

\begin{tabular}{ccc}
\hline Material & Dielectric Constant & Reference \\
\hline Zeolites & $1.5-5.0$ & {$[81]$} \\
$\mathrm{SiO}_{2}$ & 4 & {$[65]$} \\
$\mathrm{Al}_{2} \mathrm{O}_{3}$ & $9-10$ & {$[65]$} \\
$\mathrm{YSZ}$ & 27 & {$[65]$} \\
$\mathrm{TiO}_{2}$ & 48 & {$[81]$} \\
$\mathrm{CaTiO}_{3}$ & $200-300$ & {$[65]$} \\
$\mathrm{BaTiO}_{3}$ & $4000-15,000$ & {$[65]$} \\
\hline
\end{tabular}

According to Equation (17), the higher is the dielectric constant of the pellets used as a reactor packing, the higher is the reduced electrical field for a given voltage $V$ and a gap between electrodes $d$.

The use of a ferroelectric material in the packing enhanced the EE of $13 \mathrm{eV} /$ molecule at a $\mathrm{CH}_{4}$ conversion of around 55\% [82]. The authors observed a higher $\mathrm{CH}_{4}$ conversion over the packed bed and explained the results by a slower rate of the backward reaction of $\mathrm{CH}_{3}$ and $\mathrm{H}$. A mechanism of ferroelectric polarization was proposed by Chung at al. [12] (Figure 5). It was shown that without discharge, neither polarization nor electrostatic force exists between ions and electrons in the ferroelectric. Due to the external electric force, $\mathrm{Ba}^{2+}, \mathrm{Ti}^{4+}$ and $\mathrm{Zr}^{4+}$ ions are attracted by the external electrostatic field from the direct current source, and the oxygen $\mathrm{O}^{-2}$ anions are attracted by the external field of the ground electrode. The movement of anions and cations to the opposite directions causes polarization in the ferroelectric. In contrast to the dielectrics which polarization disappears as the external electric field 
is off, the ferroelectric materials preserve partly their polarization which is possible due to their specific crystalline structure. A remnant polarized ferroelectric surface has opposing positive and negative charges, first of them attracts anions, including free electrons. This results in free electron acceleration by remnant polarization of ferroelectric, increasing the kinetic energy of free electrons. This, consequently, favors vibrational excitation, dissociation and ionization in the discharge region. Chung at al. [12] claim that Packing the spark discharge reactor with ferroelectric increases the power consumption from $26.6 \mathrm{~W}$ to $39.3 \mathrm{~W}$, resulting in an increase of both $\mathrm{CH}_{4}$ and $\mathrm{CO}_{2}$ conversions. The enhancement of the $\mathrm{CO}$ generation, $\mathrm{CO}_{2}$ dissociation as well as increasing of $\mathrm{H}_{2}$ selectivity in a ferroelectric-packed bed was observed.

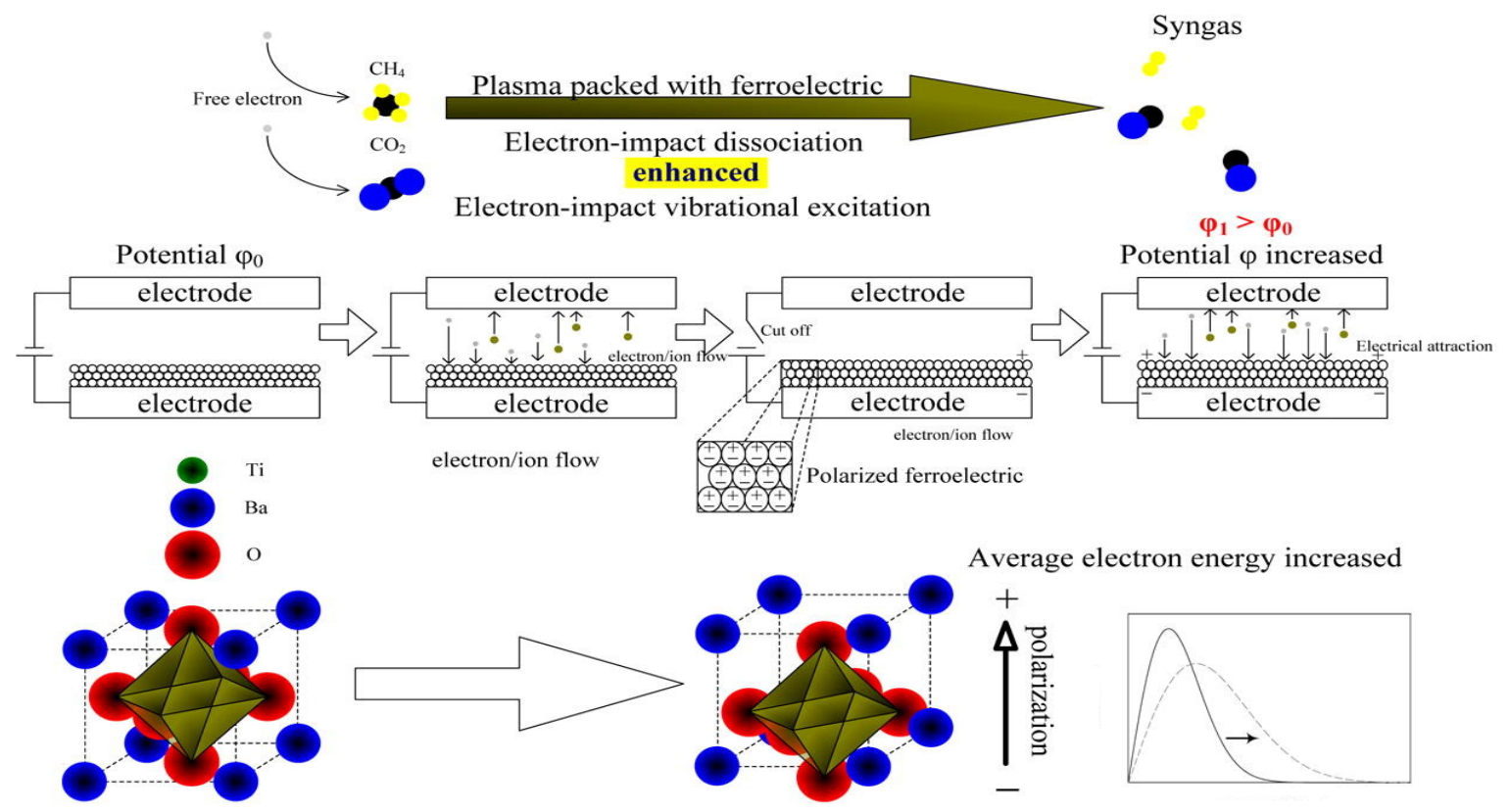

Figure 5. Mechanism of ferroelectric polarization and its effect on reforming. Reproduced with permission from [12]. Copyright 2020, Elsevier.

For $\mathrm{BaTiO}_{3}$ the transition to the streamer regime does not occur. This indicates that the majority of the charges that are generated in plasma is trapped by the packing material at the edges of the pellet i.e., plasma does not propagate between the electrodes, but between the edges of the pellets and the electrodes. Some typical examples of plasma DRM reactors with ferroelectric materials and the corresponding experimental conditions are listed in Table 6.

Table 6. Examples of plasma DRM reactors with ferroelectric materials and corresponding experimental conditions.

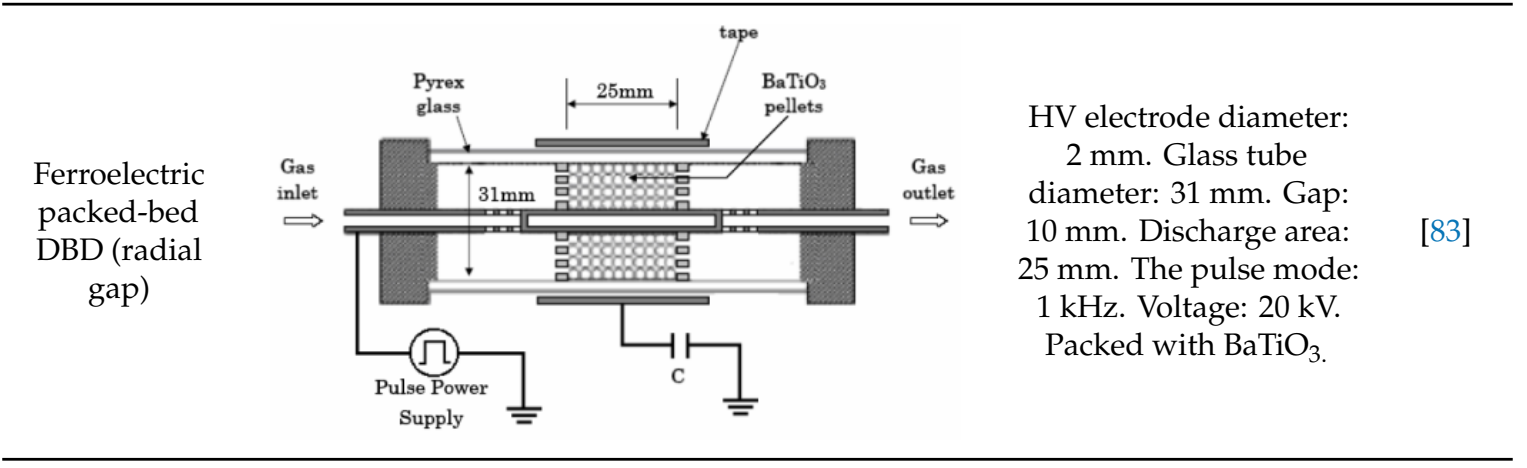


Table 6. Cont.

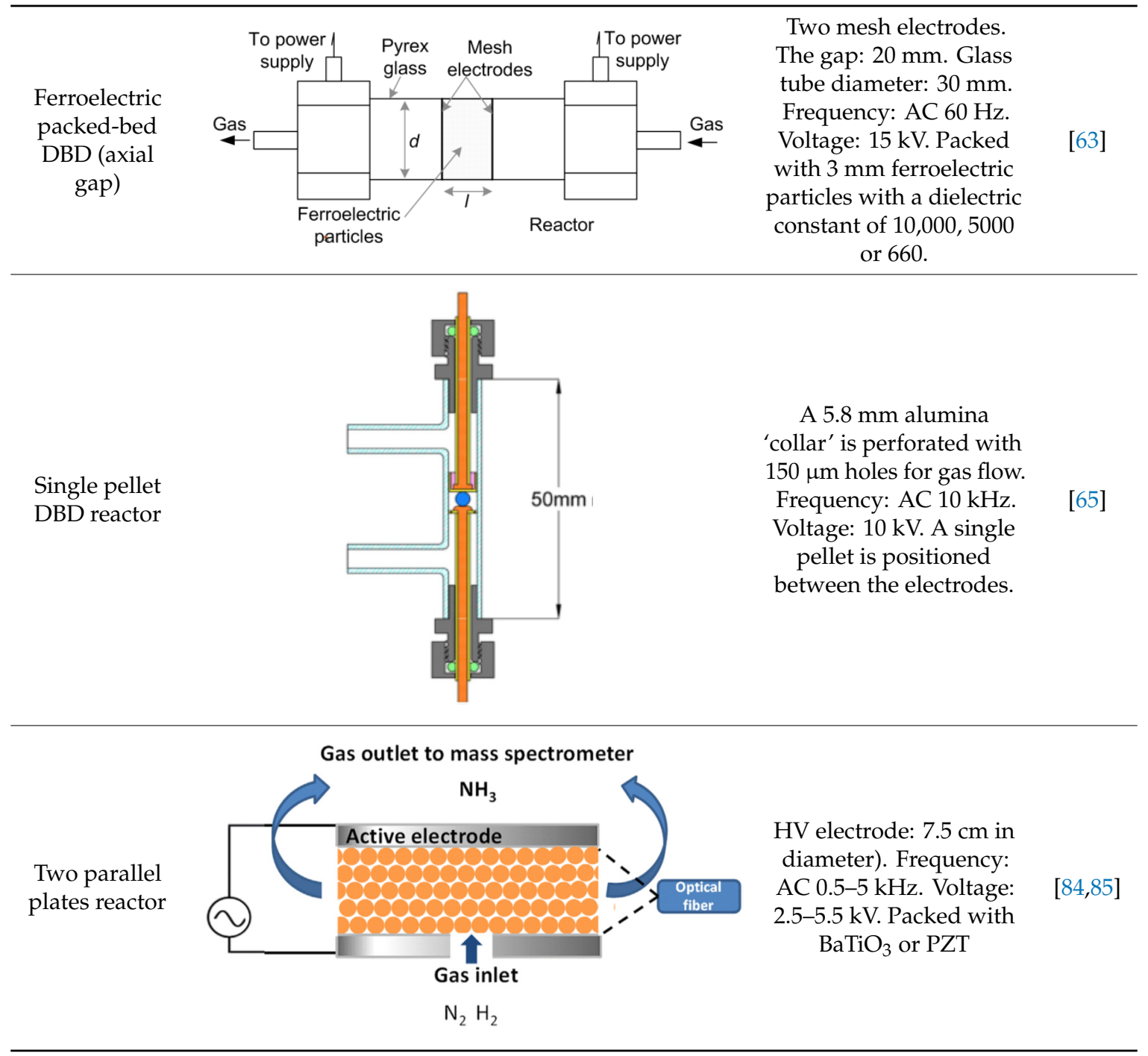

\section{Plasma-Catalysis Synergy}

The synergetic effect of plasma and catalysis is schematically shown in Figure 6. The NTP alters the physicochemical characteristics of the catalyst via several routes mainly induced by the generation of high energy electrons. The plasma changes the properties of the catalyst surface, which leads to different adsorption and desorption rates. The surface morphology of a catalyst plays a key role in determining the activity, selectivity, and stability of the catalyst. HRSEM images in combination with EDX and elemental analysis revealed that polymer-like layers with a high content of hydrogen (60 at.\%), were deposited onto the surface in the course of reaction [86]. Cheng et al. also treated supported $\mathrm{Ni}$ catalysts with DBD plasma and found an increase in the catalytic activity and stability for the partial oxidation of $\mathrm{CH}_{4}$ [87]. The SEM images supported a case for enhanced dispersion and increased interaction between the $\mathrm{Ni}$ metal and the $\mathrm{Al}_{2} \mathrm{O}_{3}$ support. These authors also reported a reduction in the formation of the carbon layer around the Ni nanoparticles. The species adsorbed onto the catalyst surface participate in reactions with the electrons and other ions that reach the surface. Thus, the probability of electron impact reactions increases as compared to the system without a catalyst. Liu et al. [88] studied the influence of NTP on the catalytic properties of alumina supported Pt, Pd, and Ni catalysts. These authors reported that the plasma treatment could remarkably enhance the dispersion of the metal on the support surface, increasing the activity of the catalyst at low temperatures by generating and redistributing the acidic and basic sites, as well as improving the catalyst stability. 


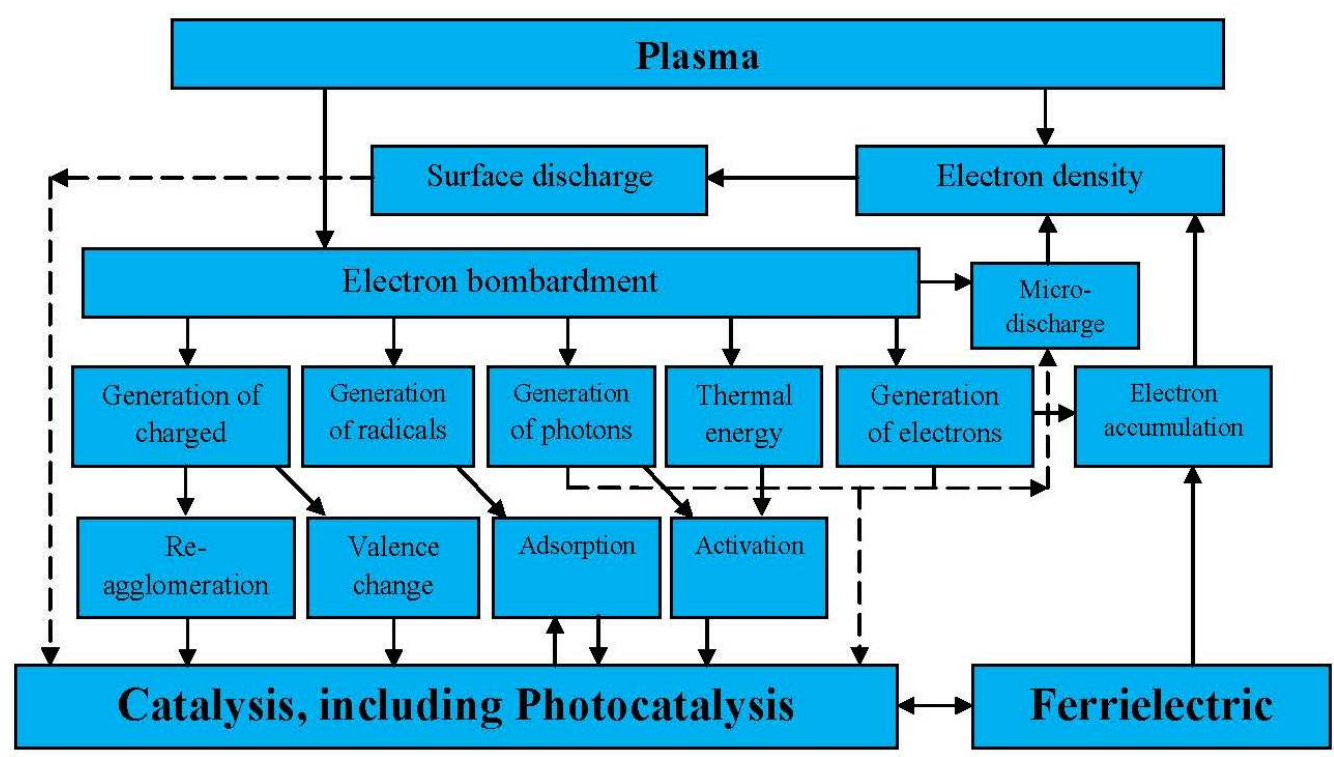

Figure 6. Interactions between the catalyst and plasma, Reproduced with permission from [41]. Copyright 2020, Elsevier.

On the other hand, the catalyst can change the strength of the electric field, resulting in a different distribution of energy absorbed by plasma species influencing conversion and selectivity in DBD reactors [89]. Tu et al. [90] reported the treatment of $\mathrm{NiO} / \mathrm{Al}_{2} \mathrm{O}_{3}$ using $\mathrm{H}_{2} / \mathrm{Ar} \mathrm{DBD}$ plasma at atmospheric pressure and a temperature below $300{ }^{\circ} \mathrm{C}$. It was found that plasma is capable of reducing $\mathrm{NiO}$ to $\mathrm{Ni}$, increasing the surface conductivity, and modifying the discharge characteristics of the plasma. Hence, both electric field distribution and the catalyst activity are modified in the process. For the case, $\varepsilon_{\mathrm{p}}>>\varepsilon_{\mathrm{g}}$, the electric field increases by 1.5 times, $E_{\mathrm{x}} \approx 1.5 \mathrm{~V} / \mathrm{d}$ (see Equation (17)). Enhancement of the electric field in catalytic reactors would result in higher electron energy. However, the electron density is inversely proportional to $E_{x}$. Therefore increasing $E_{x}$ results in a lower electron density compared to that of an empty reactor [91]. The catalyst packing can concentrate the energy inside the catalyst pores as well as between the individual particles.

The presence of the solid particles of $\mathrm{BaTiO}_{3}, \alpha$-alumina or silica-SBA-15 having a characteristic dimension of 100-300 $\mu \mathrm{m}$ and their interactions with the plasma discharges shifted the distribution of $C_{2}$-hydrocarbons [89]. The electron impact excitation, dissociation and ionization take place more frequently due to a higher local electron density.

Being different from other plasma reactors, DBD reforming has a higher $\mathrm{C}_{2} \mathrm{H}_{6}$ selectivity. High selectivity to of hydrocarbons is attributed to a partial dissociation of $\mathrm{CH}_{\mathrm{x}}$ producing large amounts of $\mathrm{CH}_{3}$ radicals that recombine to form hydrocarbons such as $\mathrm{C}_{2} \mathrm{H}_{6}$.

Applying catalysis to NTP chemistry has become increasingly popular in recent years, with catalysts offering a degree of control over selectivity in processes which are notoriously difficult to control [92]. Whilst selectivity was the main focus in catalytic reactions combined with NTP, an increase in process efficiency can also be observed if the catalyst is carefully selected [93]. The two main methodological branches are in-plasma catalysis and post-plasma catalysis. These two variations on catalytic plasma processing concern interactions of the catalyst with different species, as the timescale of plasma processes is generally in the order of few milliseconds, therefore many of the reactive species which would be present in the case of in-plasma processes will no longer be available for post-plasma catalysis.

\subsection{In-Plasma Catalysis Mode}

An important advantage of DBD plasma reactor type is the ability to change the plasma properties by incorporation of packing materials and catalysts together with optimal discharge chamber characteristics, feed gas space velocity and improved electrode morphology. The DRM 
catalysts studied in DBD reactors were considerably different in terms of the support, the specific surface area, the size of pores and metal particles, the type of metal, dielectric constant, etc. Figure 7 gives a few examples of catalyst-plasma synergy in a DBD reactor. However, it is important to mention that the materials with a similar composition can also diminish the EE by reducing the conversion of $\mathrm{CO}_{2}$ and $\mathrm{CH}_{4}[10,94]$. When $\gamma-\mathrm{Al}_{2} \mathrm{O}_{3}$ or $5 \% \mathrm{Ni} / \gamma-\mathrm{Al}_{2} \mathrm{O}_{3}$ were packed in the DBD reactor, the $\mathrm{CH}_{4}$ conversion decreased from 57.6 to $50.26 \%$ and $55.7 \%$ respectively [94].

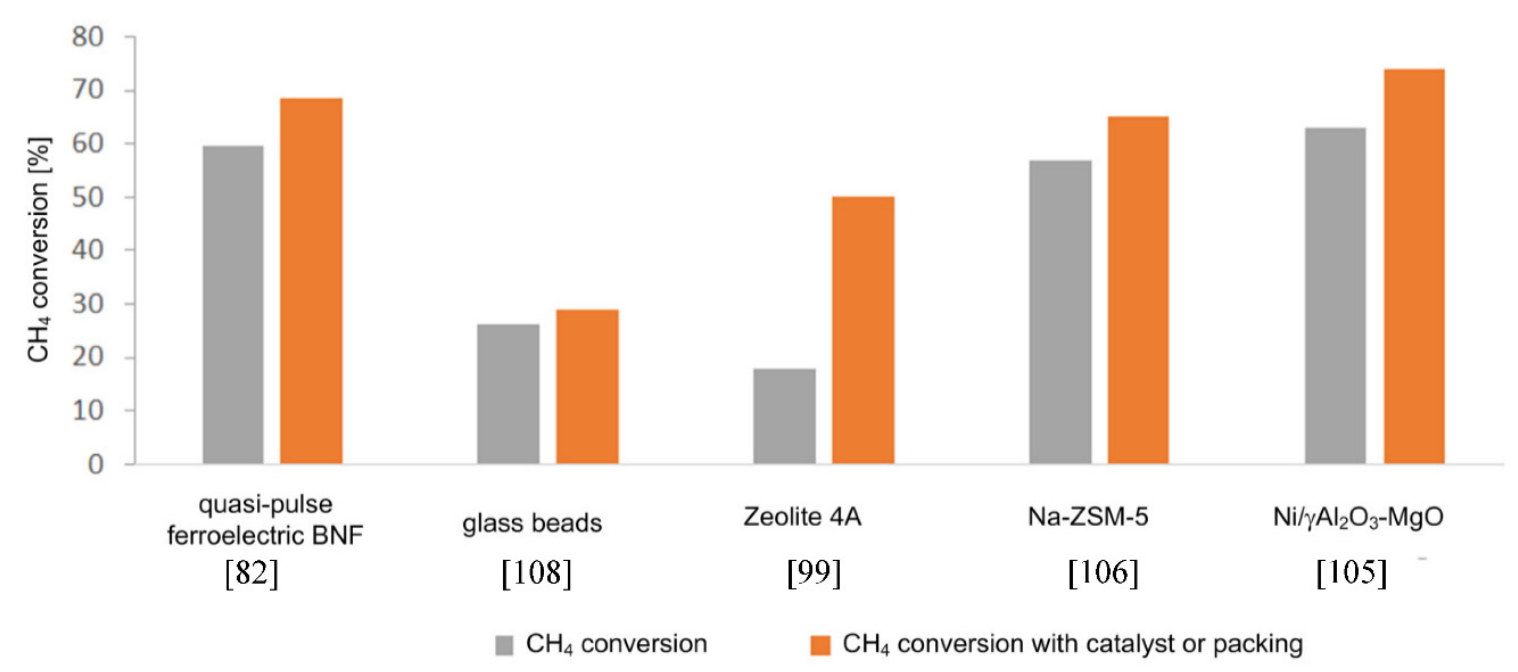

Figure 7. Influence of the packing material on $\mathrm{CH}_{4}$ conversion.

Metals supported on porous supports are among the most studied catalysts in plasma operations. Among them, Ni-based catalysts, both unpromoted ones and doped with $\mathrm{Fe}, \mathrm{Co}, \mathrm{Cu}$ and $\mathrm{La}$, were extensively studied. The total metal loading is typically $10 \mathrm{wt} . \%$ or even higher. A sharp increase in $\mathrm{CH}_{4}$ conversion from 19 to $90 \%$ was observed over $\mathrm{Cu} / \gamma-\mathrm{Al}_{2} \mathrm{O}_{3}$ catalyst added to DBD plasma while the $\mathrm{CO}_{2}$ conversion slightly decreased from 10 to $6 \%$ [95]. It was demonstrated by different physical methods that weak $\mathrm{Cu}-\mathrm{CO}$ bonds provided good oxidation properties which elevated $\mathrm{CH}_{4}$ conversion [96].

Noble and rare earth metals were also used as active metals or as promoters where the bi-metallic materials demonstrated better activity and stability.

Recently, graphitic carbon nitride $\left(\mathrm{g}-\mathrm{C}_{3} \mathrm{~N}_{4}\right)$ coupled with $\mathrm{TiO}_{2}, \mathrm{ZnO}$ and $\mathrm{TiO}_{2} / \mathrm{ZnO}$ was employed in DRM reaction. The highest conversion of $\mathrm{CH}_{4}(35.5 \%)$ and $\mathrm{CO}_{2}(13 \%)$ was achieved due to the combination of acid and base properties [97]. It was claimed that the basic sites of the catalyst are responsible for $\mathrm{CO}_{2}$ conversion whereas mild acidic sites improve the conversion of $\mathrm{CH}_{4}$.

Selection of supports such as $\mathrm{Al}_{2} \mathrm{O}_{3}, \mathrm{ZrO}_{2}, \mathrm{TiO}_{2}, \mathrm{SiO}_{2}$, mixed-oxides, highly porous materials including zeolites and metal-organic frameworks, is another field of research. A higher specific surface area and a larger metal dispersion can contribute to better chemisorption and activation of reacted species. In the review of Kim et al. [81] diffusion of plasma species in the mesopores and macrospores' was discussed in detail. The diffusion length for such species as electron and $\mathrm{O}_{3}$ was estimated from 60 up to $1.5 \times 10^{5} \mu \mathrm{m}$. However, once an atom or a molecule is adsorbed on the surface, the diffusivity rapidly drops by ca. five orders of magnitude which decreases the estimated diffusion length down to $190 \mathrm{~nm}-474 \mu \mathrm{m}$. It thus remains to be confirmed that the micropores are involved in the reaction assisted by the plasma species.

As mentioned above the dielectric constant of the catalyst also affects the properties of the plasma. Application of a ferroelectric such as $\mathrm{BaTiO}_{3}$ with the highest dielectric constant (Table 3) results in an increase in the plasma electric field [98].

By studying catalysts with very different surface areas such as $\alpha-\mathrm{Al}_{2} \mathrm{O}_{3}$ and $\gamma-\mathrm{Al}_{2} \mathrm{O}_{3}$ with the same dielectric constant it was concluded [98] that apart from differences in the discharge behavior, 
the catalytic properties related to its structure (e.g., porosity) have a vast impact on the product formation, leading to different product distribution. It has been noted that $\gamma-\mathrm{Al}_{2} \mathrm{O}_{3}$ exhibited the highest product selectivity with no detectable fractions of oxygenated products [98]. Despite this, zeolites with the lowest dielectric constant (Table 7) can give almost the same increase in activity as ferroelectrics. Thus, the type and composition of the catalysts can affect the properties of the DBD plasma in different ways, leading to the same result of increasing the $\mathrm{CH}_{4}$ and $\mathrm{CO}_{2}$ conversion.

An overview of different catalysts types used in DBD plasma DMR is given in Table 6 with the studies sorted according to achieved $\mathrm{CH}_{4}$ conversion. Other detailed summaries can be found in the reviews of Khoja et al. [61], Puliyalil et al. [13] and especially in the study of Michielsen et al. [98] where more than 50 catalysts are summarized.

An important note of such comparisons can be that significant differences in conversion and selectivity were achieved, even for similar catalysts under similar SED. The methane conversion can vary from 14 up to $82 \%$ with $\mathrm{H}_{2}$ selectivity being in the range of $8-73 \%$.

The highest $\mathrm{CH}_{4}$ conversion of $80-82 \%$ was obtained in a broad range of process parameters such as a pulsed power supply or AC, discharge gap 3-8 mm, GHSV $436-53,000 \mathrm{~h}^{-1}$, frequency $7.5-16 \mathrm{kHz}$ and SED 16-160 J/mL. The result can be explained by differences in the particle size, the reactor setup and power source parameters which determine the DRM process in DBD plasma to a larger extent than the catalytic properties per se.

According to calculations of the efficiency on the basis of Equation (14) the highest efficiency of $41 \%$ was achieved with $50 \% \mathrm{CH}_{4}$ conversion using a relatively large reactor with $330 \mathrm{~mL}$ catalyst load and a $15 \mathrm{~mm}$ discharge gap [99].

Another significant issue is coke formation during plasma-assisted DRM for both operation modes, i.e., thermal-catalytic and plasma-assisted $\mathrm{CH}_{4}$ conversion. In the former case disproportionation of $\mathrm{CO}$ (reaction 4) and $\mathrm{CH}_{4}$ cracking (reaction 5) contribute mostly to coke formation with $\mathrm{CO}$ disproportionation being a more feasible option according to thermodynamic calculations for the process below $700{ }^{\circ} \mathrm{C}[41]$.

In the comparison of the spent Ni-based catalysts supported on $\gamma-\mathrm{Al}_{2} \mathrm{O}_{3}, \mathrm{MgO}, \mathrm{SiO}_{2}$ and $\mathrm{TiO}_{2}$ the catalyst deposited on $\mathrm{Ni} / \gamma-\mathrm{Al}_{2} \mathrm{O}_{3}$ displayed the lowest carbon deposition of $3.8 \%$ after $150 \mathrm{~min}$ DRM in a DBD reactor [100]. This sample had the highest strong basic sites concentration together with a large specific surface area and small $\mathrm{NiO}$ crystallites. The highest coke content of $5.3 \$$ was observed for $\mathrm{TiO}_{2}$ as support. The increase of SED from 36 to $72 \mathrm{~J} / \mathrm{mL}$ negatively affected the carbon balance decreasing it from $96.4 \%$ to $92 \%$ for $\mathrm{Ni} / \gamma-\mathrm{Al}_{2} \mathrm{O}_{3}$. This difference in the carbon balance might be also assigned to adsorption of higher $\mathrm{C}_{5+}$ hydrocarbons and liquid oxygenates on the catalyst [100].

Addition of $\mathrm{La}_{2} \mathrm{O}_{3}$ as a co-support to $\mathrm{Ni} / \mathrm{MgAl}_{2} \mathrm{O}_{4}$ catalyst enhanced the nickel-support interactions and catalyst basicity positively influencing the coke resistance of the catalyst [101]. Prolonged catalyst stability (by $15 \mathrm{~h}$ ) can be explained by a plausible involvement of carbon deposited on the support surface with $\mathrm{O}^{*}$ species giving $\mathrm{CO}$. In the case of $\mathrm{La}_{2} \mathrm{O}_{3}$, formation of an intermediate compound, $\mathrm{La}_{2} \mathrm{O}_{2} \mathrm{CO}_{3}$, occurs by a reaction of the oxide with $\mathrm{CO}_{2}$ chemisorption followed by regeneration of $\mathrm{La}_{2} \mathrm{O}_{3}$ through a reduction with carbon. Repetition of three cycles with the catalyst regeneration by air in-between the cycles did not result in the full catalyst recovery, where in the first run, lasting $24 \mathrm{~h}$, conversion of methane decreased from $86 \%$ to $78 \%$ and from $85 \%$ to $69 \%$ during the third run with a $20 \mathrm{~h}$ duration. The results can be ascribed to the changes in structure and morphology during regeneration under air [101]. 
Table 7. An overview of different DMR catalysts used in DBD reactors.

\begin{tabular}{|c|c|c|c|c|c|c|c|c|c|c|}
\hline \multirow[b]{2}{*}{ Catalyst } & \multirow[b]{2}{*}{ Reactor } & \multirow{2}{*}{$\begin{array}{l}\text { Reaction } \\
\text { Conditions }\end{array}$} & \multirow{2}{*}{$\begin{array}{l}\text { SED } \\
{[\mathrm{J} / \mathrm{mL}]}\end{array}$} & \multicolumn{2}{|c|}{ Conversion [\%] } & \multicolumn{3}{|c|}{ Selectivity } & \multirow{2}{*}{$\begin{array}{c}\text { EE [\%, } \\
\text { (eV/Molecule)] }\end{array}$} & \multirow[b]{2}{*}{ Reference } \\
\hline & & & & $\mathrm{CH}_{4}$ & $\mathrm{CO}_{2}$ & $\mathbf{H}_{2}$ & $\begin{array}{c}\mathrm{H}_{2} / \mathrm{CO} \\
\text { Ratio }\end{array}$ & $\begin{array}{l}\text { Oxygenates and } \\
\text { Hydrocarbons }\end{array}$ & & \\
\hline $\mathrm{Cu} / \gamma-\mathrm{Al}_{2} \mathrm{O}_{3}$ & $\begin{array}{c}\text { DBD AC, } 1_{\text {gap }}=2.5 \mathrm{~mm} \\
\mathrm{~V}_{\mathrm{d}}=25 \mathrm{~mL}\end{array}$ & GHSV $=242 \mathrm{~h}^{-1}$ & 34 & 90 & 6 & - & - & & $14.5 \%$ & [95] \\
\hline $\mathrm{LaFeO}_{3}$ & $\begin{array}{c}\text { DC pulse DBD, } \\
\text { lgap }_{\text {gap }}=8 \mathrm{~mm} \\
\mathrm{~V}_{\mathrm{d}}=0.23 \mathrm{~mL}\end{array}$ & $\begin{array}{c}\text { GHSV }= \\
53,000 \mathrm{~h}^{-1}, 16 \mathrm{kV} \\
20 \mathrm{kHz}\end{array}$ & 16 & 82 & 0 & 73.1 & 1 & - & $28 \%$ & [102] \\
\hline $\mathrm{La}_{2} \mathrm{O}_{3} \mathrm{Ni} / \mathrm{MgAl}_{2} \mathrm{O}_{4}$ & $\begin{array}{c}\text { DBD AC, } 1_{\text {gap }}=3 \mathrm{~mm}, \mathrm{~V}_{\mathrm{d}} \\
=13.2 \mathrm{~mL}\end{array}$ & $\begin{array}{c}\text { GHSV }=436 \mathrm{~h}^{-1}, \\
7.5 \mathrm{kHz}\end{array}$ & 360 & 81 & & 48.1 & 1.01 & - & $1.2 \%$ & [103] \\
\hline $\mathrm{NiFe}_{2} \mathrm{O}_{4} / \mathrm{SiO}_{2}$ & AC DBD. $l_{\text {gap }}=2 \mathrm{~mm}$ & GHSV $=110 \mathrm{~h}^{-1}$ & 240 & 80 & 70 & 81 & 0.9 & - & $1.9(74)$ & [104] \\
\hline $10 \% \mathrm{Ni} / \mathrm{Al}_{2} \mathrm{O}_{3}-\mathrm{MgO}$ & $\begin{array}{c}\text { DBD AC, } 1_{\text {gap }}=3 \mathrm{~mm} \\
\mathrm{~V}_{\mathrm{d}}=13 \mathrm{~mL}\end{array}$ & $\mathrm{GHSV}=436 \mathrm{~h}^{-1}$ & 300 & 74 & & 46.0 & - & - & $1.4 \%$ & [105] \\
\hline $\begin{array}{c}\text { Ferroelectrics } \\
\mathrm{BaFe}_{0.5} \mathrm{Nb}_{0.5} \mathrm{O}_{3}\end{array}$ & $\begin{array}{c}\text { DBD AC quasi-pulse } \\
\text { power supply, } 1_{\mathrm{g}}=6 \mathrm{~mm} \\
\mathrm{~V}_{\mathrm{d}}=11.8 \mathrm{~mL}\end{array}$ & GHSV $=202 \mathrm{~h}^{-1}$ & 34 & 68 & 56 & 66.0 & 1.81 & - & $11 \%(12.5)$ & {$[82]$} \\
\hline $\begin{array}{c}\mathrm{LaNi}_{2} \mathrm{O}_{3} / \mathrm{SiO}_{2} \text { nano } \\
\text { particles }\end{array}$ & $l_{\text {gap }}=2 \mathrm{~mm}$ & $\begin{array}{c}\text { GHSV }=176 \mathrm{~h}^{-1} \\
40 \mathrm{kV}\end{array}$ & 192 & 67 & & 72.0 & & - & $1.9 \%$ & [104] \\
\hline Na-ZSM-5 & $\begin{array}{l}\text { AC. cylindrical DBD with } \\
\text { ext. heater, } l_{\text {gap }}=3 \mathrm{~mm}\end{array}$ & $\begin{array}{l}\mathrm{GHSV}=30 \mathrm{~h}^{-1}, \\
240^{\circ} \mathrm{C}, 6 \mathrm{kHz}\end{array}$ & 72 & 65 & & 21.3 & & $\begin{array}{l}\text { Among the } \\
\text { organic products, } \\
\text { ethane and } \\
\text { propane were } \\
\text { dominant }+ \\
\text { alcohols }\end{array}$ & $2.5 \%$ & [106] \\
\hline $10 \% \mathrm{Ni} / \mathrm{Al}_{2} \mathrm{O}_{3}$ & $1_{\text {gap }}=0.4 \mathrm{~mm}$ & $\begin{aligned} \text { GHSV } & =21,600 \mathrm{~h}^{-1}, \\
& 40 \mathrm{kV}\end{aligned}$ & 13 & 63 & & 35.0 & & - & $11.6 \%$ & [107] \\
\hline $10 \% \mathrm{Ni} / \gamma-\mathrm{Al}_{2} \mathrm{O}_{3}$ & $\begin{array}{c}\text { DBD AC, } 1_{\text {gap }}=3 \mathrm{~mm} \\
\mathrm{~V}_{\mathrm{d}}=11.4 \mathrm{ml}\end{array}$ & $\begin{array}{l}\text { GHSV }=103 \mathrm{~h}^{-1}, \\
40 \mathrm{kV}, \mathrm{T}=300^{\circ} \mathrm{C}\end{array}$ & 60 & 56 & 30 & 31 & 0.6 & - & $5.1 \%(32)$ & [56] \\
\hline Zeolite 4A & $\begin{array}{c}\text { AC DBD. } \\
\text { cylinder-wire-type DBD, } \\
l_{\text {gap }}=15 \mathrm{~mm}, \\
\mathrm{~V}_{\mathrm{d}}=330 \mathrm{~mL}\end{array}$ & $\begin{array}{c}\mathrm{GHSV}=109 \mathrm{~h}^{-1} \\
12 \mathrm{kV}, 0.9 \mathrm{kHz}\end{array}$ & 7 & 50 & & 59.6 & 1.28 & - & $41 \%$ & [99] \\
\hline
\end{tabular}


Table 7. Cont.

\begin{tabular}{|c|c|c|c|c|c|c|c|c|c|c|}
\hline \multirow[b]{2}{*}{ Catalyst } & \multirow[b]{2}{*}{ Reactor } & \multirow{2}{*}{$\begin{array}{l}\text { Reaction } \\
\text { Conditions }\end{array}$} & \multirow{2}{*}{$\begin{array}{l}\text { SED } \\
{[\mathrm{J} / \mathrm{mL}]}\end{array}$} & \multicolumn{2}{|c|}{ Conversion [\%] } & \multicolumn{3}{|c|}{ Selectivity } & \multirow{2}{*}{$\begin{array}{c}\text { EE [\%, } \\
\text { (eV/Molecule)] }\end{array}$} & \multirow[b]{2}{*}{ Reference } \\
\hline & & & & $\mathrm{CH}_{4}$ & $\mathrm{CO}_{2}$ & $\mathrm{H}_{2}$ & $\begin{array}{c}\mathrm{H}_{2} / \mathrm{CO} \\
\text { Ratio }\end{array}$ & $\begin{array}{c}\text { Oxygenates and } \\
\text { Hydrocarbons }\end{array}$ & & \\
\hline $5 \% \mathrm{TiO}_{2} / \mathrm{g}-\mathrm{C}_{3} \mathrm{~N}_{4}$ & $\begin{array}{c}\text { DBD AC, } 1_{\text {gap }}=6 \mathrm{~mm}, \mathrm{~V}_{\mathrm{d}} \\
=18.4 \mathrm{~mL}\end{array}$ & GHSV $=62 \mathrm{~h}^{-1}$ & 5.4 & 38.7 & 9 & 21 & 0.45 & - & $39.5 \%$ & [97] \\
\hline $\begin{array}{l}\text { glass beads } \\
\text { (zero surface) }\end{array}$ & $\begin{array}{c}\text { DBD AC, } 1_{\text {gap }}=4.5 \mathrm{~mm} \\
\mathrm{~V}_{\mathrm{d}}=18.4 \mathrm{~mL}\end{array}$ & $\begin{array}{c}\text { GHSV }=97 \mathrm{~h}^{-1}, 0.05 \\
\mathrm{kHz}\end{array}$ & 6 & 29 & & 37.2 & 0.74 & - & $25 \%$ & [108] \\
\hline $\mathrm{BaTiO}_{2}$ & \multirow{3}{*}{$\begin{array}{c}\text { DBD AC, } 1_{\text {gap }}=4.5 \mathrm{~mm} \\
\mathrm{~V}_{\mathrm{d}}=14 \mathrm{~mL}\end{array}$} & \multirow{3}{*}{$\begin{array}{c}\mathrm{GHSV}=210 \mathrm{~h}^{-1} \\
23.5 \mathrm{kHz}\end{array}$} & \multirow{3}{*}{120} & 14 & 7 & 8.9 & 6.9 & $\begin{array}{c}\mathrm{C} 2 \mathrm{H} 612.9 \%, \\
\mathrm{C} 2 \mathrm{H} 22.2 \%, \mathrm{C} 3 \mathrm{H} 8 \\
2.9 \%, \mathrm{DME}+ \\
\mathrm{EtOH}+\mathrm{CH} 2 \mathrm{O}+ \\
\mathrm{MeOH}=1.44\end{array}$ & $0.6 \%$ & \multirow{3}{*}{ [98] } \\
\hline$\gamma \mathrm{Al}_{2} \mathrm{O}_{3}$ & & & & 32 & 14 & 8.5 & 8.3 & $\begin{array}{c}\mathrm{C} 2 \mathrm{H} 615.4 \% \\
\mathrm{C} 2 \mathrm{H} 22 \%, \mathrm{C} 3 \mathrm{H} 8 \\
0.4 \%, \mathrm{DME}+ \\
\mathrm{EtOH}+\mathrm{CH} 2 \mathrm{O}+ \\
\mathrm{MeOH}=3 \%\end{array}$ & $1.5 \%$ & \\
\hline$\alpha \mathrm{Al} 2 \mathrm{O} 3$ & & & & 33 & 23 & 8.0 & 9 & $\begin{array}{c}\text { C2H6 12.9\%, } \\
\text { C2H2 2.2\%, C3H8 } \\
2.9 \%, \text { DME + } \\
\mathrm{EtOH}+\mathrm{CH} 2 \mathrm{O}+ \\
\mathrm{MeOH}=1.44 \%\end{array}$ & $1.5 \%$ & \\
\hline $\mathrm{Ni} / \gamma-\mathrm{Al}_{2} \mathrm{O}_{3}$ & $\begin{array}{c}\mathrm{DBD}, \mathrm{l}_{\text {gap }}=2.5 \mathrm{~mm}, \\
\mathrm{~V}_{\mathrm{d}}=11.6 \mathrm{ml}\end{array}$ & GHSV $=257 \mathrm{~h}^{-1}$ & 9 & 20 & 9 & 34.0 & 1.08 & $23 \% \mathrm{C}_{2} \mathrm{H}_{6}$ & $12 \%(22.2)$ & [104] \\
\hline
\end{tabular}

notations: $\mathrm{l}_{\mathrm{g}}$ is the gap length [mm], $\mathrm{V}_{\mathrm{d}}$ is the discharge volume [ml], GHSV is the gas hourly space velocity $\left[\mathrm{h}^{-1}\right]$. 
The quest for finding an optimal catalyst composition and reaction conditions preventing significant carbon deposition during plasma-assisted DRM is still ongoing with coke resistant catalysts remaining a great challenge.

\subsection{Post-Plasma Catalysis Mode}

The purpose of post-plasma catalysis (PPC) is slightly different from that of in-plasma catalysis and, as such, it requires a different reactor design. The species involved are less reactive and the process must include multiple steps. The reaction system contains a plasma reactor in series with a downstream catalytic reactor placed after the plasma discharge region.

The plasma provides chemically reactive species for catalysis or pre-converts reactants into the easier-to-convert products to accelerate catalysis [109].

The presence of the catalyst pellets in the part of the discharge gap has been found to induce plasma physical effects, such as the enhanced local electric field by $10 \%$ due to the polarization of the catalytic materials, which increases the electron temperature and produces more energetic electrons and reactive species [110].

Due to the separation of plasma and the catalyst, both thermal and non-thermal plasma can be utilized. Because excited species generated in plasma have very short lifetimes, plasma mainly plays the role to preconvert the gas followed by feeding the preconverted mixture into the second reactor.

In the NTP- catalysis system, the long-lived reactive species produced by plasma, e.g., vibration-excited species, radicals, and ionized molecules, can react with the catalyst to induce catalytic reactions via either the Eley-Rideal or Langmuir-Hinshelwood mechanism [111].

For example, Wang et al. [48] illustrated such synergy for plasma catalysis of dry reforming methane in the single-stage system with $\mathrm{Ni} / \mathrm{Al}_{2} \mathrm{O}_{3}$ catalyst but did not observe this synergy in the two-stage system or when the catalyst is only placed at the end of the plasma zone.

The use of a $\mathrm{NiO} / \mathrm{Al}_{2} \mathrm{O}_{3}$ catalyst, placed in the afterglow of the discharge in a gliding arc reactor, was found to increase energy efficiency by over $20 \%$ in comparison to the utilization of plasma only [112]. $\mathrm{H}_{2}$ yield, along with $\mathrm{CO}_{2}$ and $\mathrm{CH}_{4}$ conversions, was also increased.

The geometry of the packing can also affect the interactions between plasma and the catalyst. In the DBD reactor, the partial packing of $\mathrm{Ni} / \gamma-\mathrm{Al}_{2} \mathrm{O}_{3}$ catalyst in the discharge gap led to an improvement in the reaction characteristics as compared to a completely packed reactor $[56,113]$. This is due to the fact that a discharge in a partially packed reactor retains a strong fibrous discharge, while a decrease in the discharge volume in a fully filled reactor changes the discharge mode to a surface discharge and a spatially limited microdischarge [56].

Ozone-assisted catalysis is another type of PPC (2-stage plasma-catalysis) $[114,115]$ The optimal position of a catalyst is an important parameter determining its performance. For example, several separate studies indicate that some catalysts $\left(\mathrm{MnO}_{2}-\mathrm{CuO} / \mathrm{TiO}_{2}, \mathrm{MnO}_{\mathrm{x}} / \mathrm{Al}_{2} \mathrm{O}_{3}\right)[116,117]$ are better as the second rather than in the first stage.

Kim et al. [118] compared direct $\mathrm{O}_{2}$ plasma and $\mathrm{O}_{3}$ injection for catalyst regeneration in $\mathrm{CO}$ oxidation. The authors applied plasma to neat oxygen in a separate line, and then generated $\mathrm{O}_{3}$ was mixed with the main gas stream before entering the catalyst bed. The $\mathrm{O}_{2}$ plasma treatment as well as ozone injection were found to be efficient in the regeneration of $\mathrm{Au} / \mathrm{TiO}_{2}$ deactivated by adsorption of volatile organic compounds.

It is known that plasma can generate UV in an air-like gas mixture, but its photon flux is too low to make any significant contribution to a catalytic reaction [119]. A combination of DBD plasma with a photocatalyst $\left(\mathrm{BaTiO}_{3}\right.$ and $\left.\mathrm{TiO}_{2}\right)$ enhanced the conversion of $\mathrm{CO}_{2}$ and energy efficiency by 2.5 fold at low temperatures $\left(\sim 150^{\circ} \mathrm{C}\right)$ compared to the plasma only case [120]. Meng et al. obtained $\mathrm{CH}_{4}$ conversion of $15 \%$ over Ti-Ga/UZSM- 5 catalyst. The photocatalyst significantly increased the energy efficiency generated during application of plasma [121]. 


\section{Time-Resolved Characterization of Plasma Intermediates}

\subsection{Optical Emission Spectroscopy (OES)}

Plasma produced by several methods has been characterized by optical emission spectroscopy (OES) [122]. This method is a sensitive and non-evasive in-situ technique to probe different constituents of plasma providing useful information on different excited states in the plasma [123]. The instrumentation associated with the OES study of plasma is very simple and straightforward which mainly involves simple optics to collect light emission from the plasma and a spectrometer to record the emission spectra. A detailed analysis of the emission lines observed at different spectral positions in the optical emission spectra reveals some important characteristics of the investigated plasma, among others the ion present and the electron temperature. Bashir et al. [123] measured spectroscopic parameters of the argon-ethylenediamine vapors inside discharge and also determined electron, excitation and rotational temperatures.

OES was also applied to determine the concentration of ozone and nitrogen oxides [94]. The emission spectra of the generated plasma are measured with a resolution of $0.5 \mathrm{~nm}$.

Ma et al. [122] have conducted OES measurements to investigate the microwave activated $\mathrm{Ar} / \mathrm{H}_{2} / \mathrm{CH}_{4}$ plasma during the chemical vapor deposition of polycrystalline diamond. The authors have monitored the emissions from electronically excited $\mathrm{H}$ and $\mathrm{Ar}$ atoms, and $\mathrm{C}_{2}$ and $\mathrm{CH}$ radicals as a function of $\mathrm{Ar}$ and $\mathrm{CH}_{4}$ flow rates, input power and pressure, and proposed that different species have different formation mechanisms since they exhibit different behavior. Zhou et al. [124] performed OES study and reported the existence of abundant $\mathrm{C}_{2}$ and $\mathrm{CH}$ radicals in $\mathrm{CH}_{4} / \mathrm{Ar}$ plasma along with $\mathrm{C}_{3}$ radicals and/or 4-carbon clusters.

The emission bands in the $\mathrm{Ar} / \mathrm{H}_{2} / \mathrm{CH}_{4}$ plasma were observed at the wavelengths between 387 and $619 \mathrm{~nm}$ [125]. The $C_{2}$ Swan system corresponding to the vibration sequences $\Delta v=+2,+1,0,-1,-2$ of the $d^{3} \prod_{g}-a^{3} \prod_{u}$ electronic transitions dominate the spectrum. These corresponding bands are observed at 436, 468,516,563, and $619 \mathrm{~nm}$, respectively. The emissions at 387 and $431 \mathrm{~nm}$ were observed from $\mathrm{CH}$ species $\left(B^{2} \Sigma^{-}-X^{2} \Pi\right)$ and $\left(A^{2} \Delta-X^{2} \Pi\right)$ [126]. The emission bands at 399 and $405 \mathrm{~nm}$ were attributed to transitions in $\mathrm{C}_{3}$ radicals $\left({ }^{1} \prod_{\mathrm{u}}-{ }^{1} \sum_{g}^{+}\right)$[127]. Due to decomposition of $\mathrm{CH}_{4}$, atomic hydrogen is produced and excited, as was evidenced by the appearance of $\mathrm{H} \alpha(656.5 \mathrm{~nm})$ [124].

In plasma at local thermodynamic equilibrium (LTE), a single temperature characterizes all internal energy modes (electronic, rotational, and vibrational). This temperature can be determined from the absolute intensity of any atomic or molecular feature, or from Boltzmann plots of vibrational or rotational population distributions. However, when considering non-equilibrium plasma flows, the three temperatures should be distinguished and determined from OES spectra.

\subsubsection{Excitation and Electron Temperatures}

While the value of excitation temperature is not always the same as the electron temperature $\left(\mathrm{T}_{\mathrm{e}}\right)$, they follow a similar trend providing useful information about the excitation or de-excitation of atomic systems. For collision-dominated atmospheric pressure plasma, it was assumed that the upper energy levels of the atomic transitions are in local thermodynamic equilibrium (LTE) and hence that the population density of these levels obeys the Boltzmann law. The Boltzmann method for evaluating excitation temperature is [128]:

$$
\ln \left(\frac{I_{i j} \lambda_{i j}}{g_{i} A_{i j}}\right)=-\frac{E_{i}}{k T_{e x t}}+C
$$

where $I_{i j}$ is the relative intensity (in arbitrary units) of the emission line between the energy levels $i$ and $j . \lambda_{i j}, E_{i}$, and $g_{i}$ represent the wavelength, excitation energy and the statistical weight of the emitted upper level $\mathrm{i}, A_{i j}$ is the transition probability of spontaneous radiative emission from the upper level $i$ to the lower level $\mathrm{j}$ and $\mathrm{C}$ is a constant. The main source of error when using expression (18) for obtaining $\mathrm{T}_{\mathrm{exc}}$ come from using inaccurate $A i j$ values [129]. 
Bashir et al. [123] used relative intensities of the lines emitted by excited argon atoms to measure excitation temperature $\left(\mathrm{T}_{\mathrm{exc}}\right)$ in the argon-ethylenediamine plasma. The authors used lines in the range 516.2-750.4 nm and obtained an excitation temperature of $0.79 \pm 0.071$ for neat Ar plasma and $0.77 \pm 0.061 \mathrm{eV}$ for argon-ethylenediamine plasma in a DBD reactor.

The electron temperature $\left(T_{e}\right)$ of plasma in a non-thermodynamic equilibrium is obtained by the modified Boltzmann equation, Equation (19):

$$
\ln \left(\frac{I_{i j} \sum_{i>j} A_{i j}}{h v_{i j} A_{i j} b_{i}}\right)=-\frac{E_{i}}{k T_{e}}+D,
$$

where $h v_{i j}$ is the energy difference between two excited states and $D$ is a constant. The summation of $\sum_{i>j} A_{i j}$ represents the sum of transition probabilities for spontaneous radiative emission from level $i$ to the lower level j. Coefficients $b_{i}=E_{i}^{a} \times P_{i}^{b}$ should be known. Here, $a$ and $b$ the fitting parameters taken from Gordillo et al. [128]. $P i$ is the effective principal quantum number for the excited argon species.

Applying Equation (19), Bashir et al. [123] obtained an electron temperature of $0.92 \pm 0.16$ for neat Ar plasma and $0.84 \pm 0.14 \mathrm{eV}$ for argon-ethylenediamine (Ar/EDA) plasma in a DBD reactor. The value for neat Ar plasma is in good agreement with the maximum value of the numerically calculated electron temperature. The electron and excitation temperatures were increased by increasing the plasma power, which was attributed to an increase in the electron energy provided by the enhanced electric field at a higher discharge power.

Using Equation (18), Sohbatzadeh et al. [130] reported an excitation temperature of $1.36 \mathrm{eV}$ in an $\mathrm{RF}$ atmospheric pressure $\mathrm{Ar} / \mathrm{CH}_{4}$ plasma jet reactor (RF-APPJ) operated in the open air. The RF-APPJ was driven by a radio frequency (RF) power supply at $13.56 \mathrm{MHz}$. The gases $\left(\mathrm{CH}_{4}\right.$ and $\left.\mathrm{Ar}\right)$ were fed via an alumina ceramic tube with a length of $100 \mathrm{~mm}$, and an internal diameter of $10 \mathrm{~mm}$.

\subsubsection{Rotational Temperature}

The plasma rotational temperature was estimated based on the rotational fine structure of the electronic band $B^{2} \sum_{u}^{+}-X^{2} \sum_{g}^{+}$for $N_{2}^{+}$(so-called first negative system, the adsorption bands in the range 388.74-390.49 nm). Depending on the rotational energy states the rotational spectrum is resolved into branches of different wavelengths ( $R$ and $P$ branches) that are closely spaced. In the $R$ branch, the rotational quantum number in the ground state is one more than that in the excited state. In the $P$ branch, the quantum number in the ground state is one less than that in the excited state. The rotational temperature can be determined either using the $\mathrm{P}$ or the $\mathrm{R}$ branch. The intensity of rotational line for a transition $J^{\prime}-J^{\prime \prime}$ is represented as a function of oscillator strength $S_{J}$ [131]. The latter is equal to $\left(K^{\prime \prime}+1\right)\left(K^{\prime \prime}+2\right)$, where $K^{\prime \prime}$ represents the quantum number assigned to the lower state. Equation (20) is used to find the rotational temperature $\left(T_{r o t}\right)$ for R-branch

$$
\ln \left(\frac{I}{2\left(K^{\prime \prime}+1\right)}\right)=-\frac{B_{v} h c}{k T_{\text {rot }}}\left(K^{\prime \prime}+1\right)\left(K^{\prime \prime}+2\right)+E,
$$

where $I$ is the line intensity, $B_{v}$ is the rotational constant associated with the vibrational quantum number $v, h$ is Planck's constant, $c$ is the velocity of light and $E$ is a constant.

Collisions involving electrons do not change the rotational temperature of the molecules due to a comparatively low mass of electrons. The major contribution to the rotational temperature comes from collisions between heavy particles. Hence, the rotational temperature is considered to be an estimation of the plasma gas temperature due to a fast rotational relaxation at atmospheric pressure [132]. The rotational temperatures for neat $\mathrm{Ar}$ and $\mathrm{Ar} / \mathrm{EDA}$ plasma were reported to be $338 \pm 24 \mathrm{~K}$ and $320 \pm 28 \mathrm{~K}$, respectively [123]. The Ar plasma value was in a good agreement with the one reported by Yuan et al. [133] who employed emission bands at $431.41 \mathrm{~nm}(\mathrm{CH})$ and $516.53 \mathrm{~nm}\left(\mathrm{C}_{2}\right)$ to study the analytical characteristics for detection of organic species in Ar plasma. Stere et al. [134] 
calculated a rotational gas temperature of $91^{\circ} \mathrm{C}$ in NTP-activated hydrocarbon selective catalytic reduction in a DBD reactor operated at $6 \mathrm{kV}$. The temperature was slightly higher $\left(102{ }^{\circ} \mathrm{C}\right)$ when the discharge voltage was increased to $7 \mathrm{kV}$. The authors used the second positive system (SPS) of a molecular band $\mathrm{N}_{2}(377-381 \mathrm{~nm})$ for the calculation of rotational temperature.

\subsubsection{Vibrational Temperature}

Plasma vibrational temperature $\left(\mathrm{T}_{\mathrm{vib}}\right)$ can be estimated using the first negative system of the molecular ion of nitrogen, $N_{2}^{+}$, described in Section 7.1.2, or from the second positive system (SPS) of a molecular band $\mathrm{N}_{2}$ which has multiple bands in the range of $367.06-380.37 \mathrm{~nm}$. The second positive system of the molecular band $\mathrm{N}_{2}$ is one of the most intense band of the plasmas containing nitrogen and is found at a wide range of plasma conditions where dinitrogen is added to the gas mixture. Using this system, the rotational temperature can be calculated from the emission process: $B_{u}^{2+}-X_{g}^{2+}+h v$, where the molecular ionic state $X^{2} \sum_{g}^{+}$occurs as a result of the direct ionization by an electronic impact of the basic $\mathrm{N}_{2}$ state, $X^{1} \sum_{g}^{+}$. The vibrational temperature is calculated following [132]

$$
\ln \left(\frac{I_{\gamma^{\prime} \gamma^{\prime \prime}} \lambda_{\gamma^{\prime} \gamma^{\prime \prime}}}{A_{\gamma^{\prime} \gamma^{\prime \prime}} h c}\right)=-\frac{G_{\nu} h c}{k T_{v i b}}+F,
$$

where $\lambda_{v^{\prime} v^{\prime \prime}} I_{v^{\prime} v^{\prime \prime}}$ is the wavelength (nm) and the relative intensity of line (a.u), respectively. $G_{v}$ is the energies of the vibrational levels $\left(\mathrm{m}^{-1}\right), A_{\gamma^{\prime} v^{\prime \prime}}$ the transition probabilities $\left(\mathrm{s}^{-1}\right)$ of the $\mathrm{N}_{2}$ vibrational band and $F$ is a constant. The vibrational temperature for Ar/EDA plasma was reported to be $0.124 \mathrm{eV}$ [123]. An error of about $10 \%$ is incurred in the OES vibrational temperature measurement. Sakamoto et al. [135] used the $\mathrm{N}_{2}$ SPS to determine the vibrational temperatures of $\mathrm{N}_{2}$ in microwave plasma at low pressure. They reported a vibrational temperature of $0.5-0.7 \mathrm{eV}$ at an output power of $600 \mathrm{~W}$ at $2.45 \mathrm{GHz}$. These authors observed a large contribution form from the upper electronic states to the vibrational state as their theoretical results were not in line with their OES experiments.

Kinoshita et al. [136] studied the influence of the airflow velocity and ambient pressure on the vibrational and rotational temperatures in a spark-discharge plasma using OES. At the center of the spark plug gap, the vibrational temperature was $4000 \mathrm{~K}$, whereas the rotational temperature was $2000 \mathrm{~K}$. However, at a position of $3 \mathrm{~mm}$ downstream from the spark plug gap, the vibrational and rotational temperatures increased to 4500 and $4000 \mathrm{~K}$, respectively, approaching each other. These results showed that the plasma state undergoes a transition from non-thermal equilibrium to thermal equilibrium along the flow direction (Figure 8). The collision frequency between the plasma and the neutral molecules increases downstream from the spark plug gap. As a result, energy relaxation occurs [137]. The electronic energy is transformed to vibrational energy, and as a result, the vibrational temperature increases because of the energy relaxation by the electrons. Furthermore, the rotational temperature also increases because of the collision relaxation between the vibration excitation molecules.

In non-equilibrium plasma, it can be assumed that the rotational temperature is close to the gas temperature because rotational relaxation is fast at atmospheric pressure. However, no assumption holds regarding the vibrational and electronic population distributions. An assumption that the electron temperature and vibrational temperature are approximately equal to the electron temperature is not always valid in non-equilibrium plasmas. In fact, it has been shown that such an assumption is incorrect in $\mathrm{CH}_{4} / \mathrm{Ar} \mathrm{DBD}$ and plasma jet at atmospheric pressure. The temperature in these cases obey the classical sequence of non-thermal plasma $\left(\mathrm{T}_{\mathrm{e}}>\mathrm{T}_{\mathrm{exc}}>\mathrm{T}_{\mathrm{vib}}>\mathrm{T}_{\text {rot }}\right)$. 


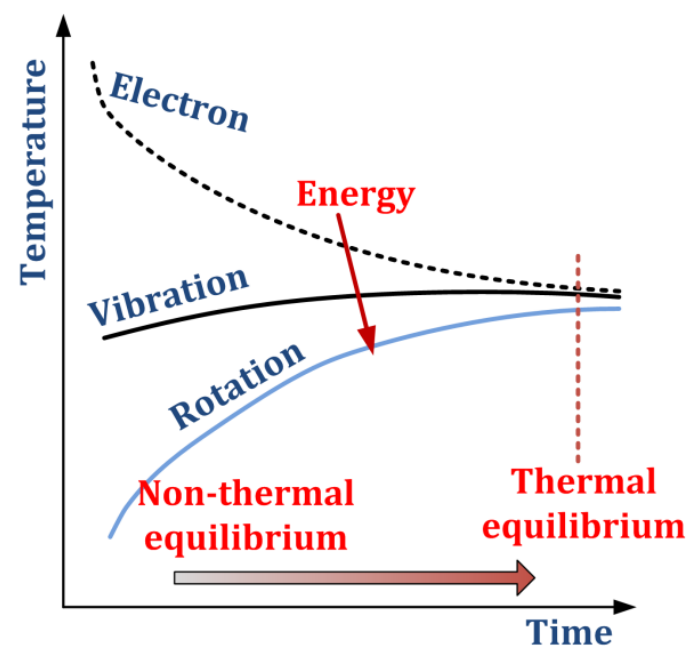

Figure 8. Energy relaxation in spark-discharge plasma. The picture was drawn by the authors using the data from [136].

\subsection{FTIR-Spectroscopy}

FTIR spectroscopy is used to monitor the progress of the reaction and identify the various intermediate species that are formed during the course of the reaction. Majority of molecules in NTP-plasma absorb mid-infrared light, making FTIR a highly useful tool. However in-situ studies on the catalyst surface in contact with plasma have started to appear only very recently. Rodrigues et al. [138] used operando DRIFT spectroscopy characterization of intermediate species on the catalyst surface during NTP assisted catalysis. Jia and Rousseau demonstrated a new reactor cell to monitor adsorption and surface oxidation of pollutants under direct plasma exposure. The principle was based on FTIR spectroscopy operating in a transmission mode [139]. A thin catalyst pellet can be inserted in a holder and then exposed to DBD plasma. The time resolution of the method is limited to that of the FTIR spectrometer (Nicolet 5700 ) being ca. $30 \mathrm{~s}$.

Stere et al. [134] developed a DRIFTS-MS system to investigate the surface changes during an NTP activated selective catalytic reduction of NOx with hydrocarbons. A dome was designed to allow a sufficient space for the plasma volume to be positioned within the cell and interact with the catalyst bed directly and at the same time allowing a line of sight for the infrared signal to pass through the windows and reflect on and off the catalyst bed. The spectra were taken when the NTP was in contact with the catalyst surface. The IR bands between 3100 and $2800 \mathrm{~cm}^{-1}$ were attributed to adsorbed and gas-phase n-octane, which was used as a reducing agent. Upon application of $5 \mathrm{kV}$ voltage, nitrate species, acetate-based species and carboxylates were observed. After $10 \mathrm{~min}$, further increases in the acetate, nitrate, and carboxylate bands were observed and the n-octane bands decreased, indicating hydrocarbon transformations. However, the flow configuration within this reactor was different from that of a fixed bed reactor typically employed for studies of plasma-catalyst interactions. In a subsequent study, these authors improved the original cell design by using a fixed bed plasma DRIFTS cell coupled with mass spectrometry, allowing in-situ DRIFTS analysis [140]. The measurements were performed using a Bruker Vertex 70 FTIR spectrometer, equipped with a liquid $\mathrm{N}_{2}$-cooled mercury-cadmium-telluride detector. The plasma was generated at a frequency of $27 \mathrm{kHz}$ with an applied voltage of 5 or $6 \mathrm{kV}$.

Nair et al. developed a DBD plasma catalytic reactor placed inside a demountable gas cell with a cell path length of $5 \mathrm{~cm}$ [141]. A glass plate of $27 \mathrm{~mm} \times 32 \mathrm{~mm} \times 2 \mathrm{~mm}$ was used as the dielectric layer and the gap distance was $4-5 \mathrm{~mm}$. The gas cell was closed on the ends by infrared (IR) transparent windows. The optical path length inside the reactor was $6.5 \mathrm{~cm}$. The plasma was generated at a frequency of 700-1200 Hz with an applied voltage of 4-6 kV. The experiments were performed at room temperature and at low energy inputs of $50 \mathrm{~kJ} / \mathrm{mol} \mathrm{CH}_{4}$ in a gas mixture containing $\mathrm{CH}_{4}\left(90\right.$ vol.\%), $\mathrm{O}_{2}$, 
and $\mathrm{N}_{2}$. In the absence of oxygen, alkanes, alkenes, and alkynes were formed as the main products. With increasing oxygen content, a gradual shift to aldehydes was observed.

While FTIR analysis provides many useful insights on the reaction dynamics and the intermediates formed on the catalyst surface, it also encounters the problems of frequent calibrations and transient errors due to the limited time resolution. Therefore real-time monitoring of short-living plasma species is not possible in the plasma-catalytic process. This approach is either not appropriate for the measurement of temperature and concentration fields, i.e., the distributions of temperature and gas concentration of key plasma intermediates. On the other hand, there were several studies applying laser technology. It has been proven that tunable diode laser absorption spectroscopy (TDLAS) is able to measure the temperature and concentrations at a fast response time [142,143].

\subsection{Tunable Diode Laser Absorption Spectroscopy (TDLAS)}

Since the plasma species are short-living, it is necessary to measure their concentrations and temperature with a $\mathrm{kHz}$ frame rate. Among all optical techniques, TDLAS is currently the most robust, convenient and economic one in real industrial environments [144]. The principle of TDLAS is based on the Beer-Lambert law. When the light permeates an absorption medium, the strength of the permeated light is related to the absorber concentration according to the Beer-Lambert s law. The main features of the TDLAS technique are its ultra-fast response and high sensitivity. TDLAS is commonly divided into two categories: direct absorption spectroscopy (DAS) in which the parameters are inferred from the direct absorption signal, and wavelength modulation spectroscopy (WMS) in which the parameters are coupled in the harmonics of the high-frequency $(>100 \mathrm{kHz}$ ) wavelength-modulated absorption signal.

For molecules such as water, ethylene and methane with dense spectral features, the selection of appropriate spectral lines for temperature (using two-line thermometry) and concentration measurements is of large importance. Sur et al. measured the molar $\mathrm{CO}, \mathrm{CO}_{2}, \mathrm{CH}_{4}$, and $\mathrm{H}_{2} \mathrm{O}$ concentrations in the 1-10 vol. \% range in the synthesis gas with an accuracy of $\pm 4 \%$ using TDLAS [143]. In these experiments, separate lasers were used for each species ( $\mathrm{CO}$ at $2.326 \mu \mathrm{m}, \mathrm{CO}_{2}$ at $2.017 \mu \mathrm{m}$, $\mathrm{CH}_{4}$ at $2.290 \mu \mathrm{m}$, and $\mathrm{H}_{2} \mathrm{O}$ at $1.352 \mu \mathrm{m}$ ) and a fiber bundle was utilized to combine all four beams on a common optical path. Single-sweep laser scanning provided a $20 \mathrm{~ms}$ time resolution. The time-averaged concentrations measured by TDLAS were in good agreement with those obtained by gas chromatography. The method enabled the identification of a wide range of dynamic behavior.

Extensive research has also been performed on the utilization of TDLAS for the fast system control. The local mass flow rate is an important parameter in plasma reactors, and is used in calculations of energy efficiency. A mass flux sensor based on TDLAS of water vapor was tested by Chang et al. to establish the measurement accuracy at velocities in the range of 2-18 m/s [145]. The line strength, air-broadening and self-broadening coefficients of two $\mathrm{H}_{2} \mathrm{O}$ absorption lines at 1.349 and $1.341 \mu \mathrm{m}$ were measured by wavelength-scanned direct absorption in a cell [146]. The uncertainties of the measured line strengths were analyzed to be less than $2 \%$. This allowed to carry out velocity measurements with a precision of $\pm 0.5 \mathrm{~m} / \mathrm{s}$ of the set point.

In the case of WMS, the variation of transmitted intensity with the wavelength is compared with spectral models to determine the gas concentration and the temperature. The most common WMS technique is the scanned-WMS, which tunes the injection current of diode laser with a low-frequency scanning signal and a high-frequency sinusoidal modulation (f). Detecting the absorption signal at the second harmonic of the high-frequency modulation provides a large increase in the signal-to-noise ratio [147]. The algorithm adopts WMS technique with normalization of the second harmonic (2f) signal by the first harmonic (1f) signal (WMS-2f/1f), and it can restrain interference caused by circuit, light path, optical source and other factors [148]. The actual gas-phase temperature and concentration are calculated by comparing the measured and simulated WMS-2f/1f signal ratio. For these calculations, the spectrum parameters, such as absorption coefficients and broadening coefficients, have to be measured in advance by IR spectroscopy. WMS was widely applied to obtain 2D maps of temperature and concentration in a reactor. To obtain a spatial distribution, eight optical probes for WMS were 
used: five positioned vertically with a spacing of $5 \mathrm{~cm}$ and three horizontally with a spacing of $3 \mathrm{~cm}$. Laser beams across the measured area were collected by multimode fibers and detected by eight InGaAs detectors at a frequency of $5 \mathrm{MHz}$. From these measurements, the temperature and water concentration were reconstructed [147]. The detection system was able to detect fast concentration switches that occured every $20 \mathrm{~ms}$. These results demonstrated the fast response speed of the WMS method.

$2 \mathrm{D}$ temperature and the concentration distributions of gas components and temperature between the electrodes of a plasma reactor play an important role in the plasma structure and the energy efficiency. Two dimensional (2D) temperature and concentration maps can be obtained by combining the TDLAS method with a set of individual detectors or a focal planar array (FPA) detector. Kamimoto et al. obtained 2 $\mathrm{D} \mathrm{CH}_{4}$ concentration distributions using a 16 path TDLAS measurement cell [149]. In another study from the same group, FB lasers at 1.388 and $1.635 \mu \mathrm{m}$ were used to measure water vapor, and $\mathrm{CH}_{4}$ concentration, respectively. The laser wavelength was scanned at $1-4 \mathrm{kHz}$ and the absorption spectra were measured simultaneously to calculate the instant $2 \mathrm{D}$ concentration and temperature using 16 path measurement cell [150]. In order to measure several different gas concentrations simultaneously, the laser light from each laser was directed into a single optical fiber by the time-division-multiplexing.

\section{Summary and Outlook}

A low selectivity to the desired products (either $\mathrm{C}_{2} \mathrm{H}_{4}$ or oxygenates) remains the main challenge in the DRM reaction. Furthermore, the energy efficiency (currently in the 12-15\% range) should be considerably enhanced. Fast development in the area of non-thermal plasma technology brings new challenges for the research community. The reactant conversion can be improved by proper reactor design, i.e., by increasing the number of molecules passing through the active plasma region. First of all, decreasing the gap size between the electrodes to the submillimeter range results in very strong interactions between the plasma species and the electrode surface. In the GA reactors, the plasma arc does not fill the entire plasma reactor volume but is mainly moving along the center axis. Therefore much gas does not pass through the plasma region. This limits the overall conversion in the reactor, except for the cases when a significant thermal conversion occurs in the region around the plasma [151]. The high energy electrons induced by high-voltage discharges in NTP generate active species (secondary electrons, ions, photons, free radicals, etc.) by electron-molecule collisions. Addition other gases such as $\mathrm{N}_{2}$ and $\mathrm{O}_{2}$ can also influence the selectivity and the EE of the process.

The plasma can overcome the usual constraints of catalysts to have low activation energy for $\mathrm{CO}_{2}$ dissociation and at the same time a weak interaction with intermediates, needed for their fast desorption. While the current review was not focused on modeling of plasma chemistry, as this is a very broad topic, probably requiring a review of its own, it became apparently clear that the current models for plasma-catalysis do not address the whole complexity of proceeding chemical reactions. As a consequence new micro-kinetic models with plasma species adsorbed on the catalyst surface have to be developed. These models can improve understanding of surface reactions which in turn may help to control the selectivity. Extended reactor models have to be developed. At present, most efforts were devoted to the modeling the volumetric plasma chemistry, mainly with zero-dimensional (time-dependent, or pseudo 1D where time was replaced with residence time) models that did not account for the actual reactor dimensions. Recently, several groups started modeling plasma reactors for gas conversion applications, with 2D fluid dynamics models. However, the impact of possible surface charging, strong electric field and excited species has not been taken into account.

The main limitation for energy-efficient $\mathrm{CO}_{2}$ conversion is the backward reaction (of $\mathrm{CO}$ with $\mathrm{O}$ atoms) and this recombination reaction becomes faster at a higher temperature. Fast cooling of the gas in the post-plasma reaction zone can reduce the rate of the backward reaction. Yang et al. [152] already demonstrated the effects of supersonic quenching for a thermal $\mathrm{CO}_{2}$ plasma. The quenching was based on the adiabatic expansion of the gas in a nozzle, yielding acceleration to sonic speed and conversion of thermal energy into kinetic energy. This was followed by a further cooling in a tube under highly turbulent flow conditions, enhancing the heat transfer rate between the gas and the 
tube surface. It was demonstrated that quenching prevents the reverse reactions, enhancing both the conversion and energy efficiency and therefore this should be extensively investigated. The same concept may be valid to GA plasmas, where the hot arc region (usually around $3000 \mathrm{~K}$ ) is surrounded by cooler gas. On the equipment design side, the heat which is recovered from quenching can be used to preheat the inlet gas mixture to reduce the power requirements. This can also increase the overall EE of the process. Therefore reaction conditions in the post-plasma region outside the plasma zone are the key for further EE and reactant conversion optimization and those should be extensively investigated.

Plasma is very reactive, but therefore it is not selective in the production of targeted molecules. So far, a combination of a catalyst with plasma was focused on the application of classical thermal catalysts, which are not most suitable for combination with plasma. As plasma is also producing UV-light, the application of photocatalysts in combination with plasma was demonstrated to improve both the selectivity and EE beyond those observed when the two methods were applied individually. For $\mathrm{CO}_{2}$ splitting and DRM reactions, the energy efficiency above $60 \%$ was shown to be possible. Very limited literature data are available describing the application of semiconductor-type catalysts under plasma conditions. This research direction needs to be extended to find more efficient catalysts that can accommodate very active plasma species on their surface and at the same time be activated by visible (or UV) light.

Second, application of the ultra-short pulses in the nanosecond range allows us to increase the efficiency of DBD reactors to the level of other types such as GA, spark and corona. While it is generally accepted that the runaway electron breakdown theory can be applied to the nanosecond pulsed discharge, generation of secondary electrons and streamer development require further investigation. The ultra-short pulse in the nanosecond range generates homogenous plasma under atmospheric pressure, which is beneficial for many chemical conversions. However, it is difficult to maintain uniform discharge when increasing the reactor volume. Therefore, the scaling rules for plasma discharge need further investigation.

Third, the application of new ultra-fast methods with a high temporal and spatial resolution is required in the area of non-thermal plasma diagnostics, both optical and electrical. The electrical diagnostic devices should be able to provide faster transient responses, to be protected against severe electromagnetic interference and allow more precise signal synchronization. To perform real-time optical monitoring of plasma species, TDLAS with a mid-infrared quantum cascade laser is a promising method enabling high spatial resolution $(15 \mu \mathrm{m} \times 15 \mu \mathrm{m})$ at a $\mathrm{kHz}$ frequency. Rapid developments in fiber optics and high-speed electronics of focal planar array (FPA) detectors allow currently to achieve time resolutions already in the millisecond range. However, several major equipment design limitations inherently associated with optical tomography are still unresolved: (1) so far water vapor and NO (nitric oxide) were used as tracers, due to their high absorption coefficient, but the applicability of other gases has not yet been demonstrated, unless a dedicated optical design (enhanced optical path, higher pressures, etc.) was applied. Therefore, the development of spatially resolved techniques, with a well-defined methodology enabling highly efficient, selective, and long-term use chemical transformations remains a paramount challenge.

Additionally to TDLAS, the emission spectra of the plasma species can be measured using commercial fiber-coupled optical emission spectrometers (OES) with a spectral range of 200-1000 nm and a resolution of $0.5 \mathrm{~nm}$. This resolution is enough to resolve the electronic temperature and electron density in plasma. However, a much higher resolution is required to resolve the vibrational and rotational temperatures of plasma species. FTIR spectroscopy can be used to monitor the progress of the reaction and identify the various intermediate species that are formed during the course of the reaction on the catalyst surface.

Thus, we can predict that the replacement of current fossil fuel technologies with those based on renewable energy sources (electrified methane reforming and processing waste $\mathrm{CO}_{2}$ to fuels and chemicals), is a key factor in the transition to a circular economy. This transition supports increasing interests in catalytic plasma technology. While many technical and economic challenges are still to 
be solved, catalytic plasma technology offers many advantages as compared to alternative solutions, as discussed in this paper.

Author Contributions: Each author has contributed equally in this paper. Particularly, R.S.A. contributed to Sections 2, 3 and 5 and Section 6 (except Section 6.2), D.A.S. and K.V.S. have prepared Sections 4, 6.2 and 7, D.Y.M. took part in preparation of Sections $4,6.2$ and 7, he was responsible for the paper consistency and E.V.R. contributed to Sections 1, 2.4, 4.2, 7 and 8, as well he was responsible for the paper strcucture and consistency, for the managing of the paper preparation and final corrections. All authors have read and agreed to the published version of the manuscript.

Funding: This research and the APC were funded by Russian Science Foundation grant number 20-69-46041.

Acknowledgments: The authors would like to thank the Russian Science Foundation (project 20-69-46041) for financial support.

Conflicts of Interest: The authors declare no conflict of interest.

\section{List of Abbreviations:}

$\begin{array}{ll}\text { AC } & \text { alternate current } \\ \text { APPJ } & \text { atmospheric pressure plasma jet reactor } \\ \text { DBD } & \text { dielectric barrier discharge } \\ \text { direct absorption spectroscopy } \\ \text { DAS } & \text { dry reforming of methane } \\ \text { energy efficiency } \\ \text { ERM } & \text { focal planar array } \\ \text { FPA } & \text { Fourier Transform Infrared Spectroscopy } \\ \text { FTIR spectroscopy } & \text { gliding arc } \\ \text { GA } & \text { gas hourly space velocity, } \mathrm{h}^{-1} \\ \text { GHSV } & \text { local thermodynamic equilibrium } \\ \text { LTE } & \text { non-thermal plasma } \\ \text { NTP-plasma } & \text { optical emission spectroscopy } \\ \text { OES } & \text { lead zirconate titanate } \\ \text { PZT } & \text { post-plasma catalysis } \\ \text { PPC } & \text { radio frequency } \\ \text { RF } & \text { specific energy density } \\ \text { SED } & \text { second positive system } \\ \text { SPS } & \text { tunable diode laser absorption spectroscopy } \\ \text { TDLAS } & \text { ultraviolet } \\ \text { UV } & \text { wavelength modulation spectroscopy } \\ \text { WMS } & \end{array}$

\section{References}

1. Faramawy, S.; Zaki, T.; Sakr, A.A.-E. Natural gas origin, composition, and processing: A review. J. Nat. Gas Sci. Eng. 2016, 34, 34-54. [CrossRef]

2. Atsonios, K.; Panopoulos, K.D.; Kakaras, E. Investigation of technical and economic aspects for methanol production through $\mathrm{CO}_{2}$ hydrogenation. Int. J. Hydrog. Energy 2016, 41, 2202-2214. [CrossRef]

3. Ashcroft, A.T.; Cheetham, A.K.; Foord, J.S.; Green, M.L.H.; Grey, C.P.; Murrell, A.J.; Vernon, P.D.F. Selective oxidation of methane to synthesis gas using transition metal catalysts. Nature 1990, 344, 319-321. [CrossRef]

4. Ashcroft, A.T.; Cheetham, A.K.; Green, M.L.H.; Vernon, P.D.F. Partial oxidation of methane to synthesis gas using carbon dioxide. Nature 1991, 352, 225-226. [CrossRef]

5. Maitra, A. Critical performance evaluation of catalysts and mechanistic implications for oxidative coupling of methane. Appl. Catal. A Gen. 1993, 104, 11-59. [CrossRef]

6. de Vekki, A.V.; Marakaev, S.T. Catalytic partial oxidation of methane to formaldehyde. Russ. J. Appl. Chem. 2009, 82, 521-536. [CrossRef]

7. Peter, A.; Mihaly-Cozmuta, A.; Nicula, C.; Mihaly-Cozmuta, L.; Jastrzębska, A.; Olszyna, A.; Baia, L. UV Light-Assisted Degradation of Methyl Orange, Methylene Blue, Phenol, Salicylic Acid, and Rhodamine B: Photolysis Versus Photocatalyis. Water Air Soil Pollut. 2017, 228, 41. [CrossRef] 
8. Tuller, H.L. Solar to fuels conversion technologies: A perspective. Mater. Renew. Sustain. Energy 2017, 6, 1-16. [CrossRef]

9. Song, H.; Meng, X.; Wang, Z.J.; Liu, H.; Ye, J. Solar-Energy-Mediated Methane Conversion. Joule 2019, 3, 1606-1636. [CrossRef]

10. Wang, L.; Yi, Y.; Wu, C.; Guo, H.; Tu, X. One-Step Reforming of $\mathrm{CO}_{2}$ and $\mathrm{CH}_{4}$ into High-Value Liquid Chemicals and Fuels at Room Temperature by Plasma-Driven Catalysis. Angew. Chem. Int. Ed. 2017, 56, 13679-13683. [CrossRef]

11. Sentek, J.; Krawczyk, K.; Młotek, M.; Kalczewska, M.; Kroker, T.; Kolb, T.; Schenk, A.; Gericke, K.-H.; Schmidt-Szałowski, K. Plasma-catalytic methane conversion with carbon dioxide in dielectric barrier discharges. Appl. Catal. B Environ. 2010, 94, 19-26. [CrossRef]

12. Chung, W.C.; Chang, M.B. Dry reforming of methane by combined spark discharge with a ferroelectric. Energy Convers. Manag. 2016, 124, 305-314. [CrossRef]

13. Puliyalil, H.; Jurković, D.L.; Dasireddy, V.D.B.C.; Likozar, B. A review of plasma-assisted catalytic conversion of gaseous carbon dioxide and methane into value-added platform chemicals and fuels. RSC Adv. 2018, 8, 27481-27508. [CrossRef]

14. Shao, T.; Wang, R.; Zhang, C.; Yan, P. Atmospheric-pressure pulsed discharges and plasmas: Mechanism, characteristics and applications. High Volt. 2018, 3, 14-20. [CrossRef]

15. Lavoie, J.-M. Review on dry reforming of methane, a potentially more environmentally-friendly approach to the increasing natural gas exploitation. Front. Chem. 2014, 2, 81. [CrossRef]

16. Arman, A.; Hagos, F.Y.; Abdullah, A.A.; Mamat, R.; Aziz, A.R.A.; Cheng, C.K. Syngas production through steam and $\mathrm{CO}_{2}$ reforming of methane over Ni-based catalyst-A Review. IOP Conf. Ser. Mater. Sci. Eng. 2020, 736, 042032. [CrossRef]

17. Abdullah, B.; Abd Ghani, N.A.; Vo, D.V.N. Recent advances in dry reforming of methane over Ni-based catalysts. J. Clean. Prod. 2017, 162, 170-185. [CrossRef]

18. Argyle, M.; Bartholomew, C. Heterogeneous Catalyst Deactivation and Regeneration: A Review. Catalysts 2015, 5, 145-269. [CrossRef]

19. Usman, M.; Wan Daud, W.M.A.; Abbas, H.F. Dry reforming of methane: Influence of process parameters-A review. Renew. Sustain. Energy Rev. 2015, 45, 710-744. [CrossRef]

20. Jang, W.J.; Shim, J.O.; Kim, H.M.; Yoo, S.Y.; Roh, H.S. A review on dry reforming of methane in aspect of catalytic properties. Catal. Today 2019, 324, 15-26. [CrossRef]

21. Aramouni, N.A.K.; Touma, J.G.; Tarboush, B.A.; Zeaiter, J.; Ahmad, M.N. Catalyst design for dry reforming of methane: Analysis review. Renew. Sustain. Energy Rev. 2018, 82, 2570-2585. [CrossRef]

22. Abdulrasheed, A.; Jalil, A.A.; Gambo, Y.; Ibrahim, M.; Hambali, H.U.; Shahul Hamid, M.Y. A review on catalyst development for dry reforming of methane to syngas: Recent advances. Renew. Sustain. Energy Rev. 2019, 108, 175-193. [CrossRef]

23. Pakhare, D.; Spivey, J. A review of dry $\left(\mathrm{CO}_{2}\right)$ reforming of methane over noble metal catalysts. Chem. Soc. Rev. 2014, 43, 7813-7837. [CrossRef] [PubMed]

24. da Fonseca, R.O.; Rabelo-Neto, R.C.; Simões, R.C.C.; Mattos, L.V.; Noronha, F.B. Pt supported on doped $\mathrm{CeO}_{2} / \mathrm{Al}_{2} \mathrm{O}_{3}$ as catalyst for dry reforming of methane. Int. J. Hydrog. Energy 2020, 45, 5182-5191. [CrossRef]

25. Zhang, R.J.; Xia, G.F.; Li, M.F.; Wu, Y.; Nie, H.; Li, D.D. Effect of support on catalytic performance of Ni-based catayst in methane dry reforming. J. Fuel Chem. Technol. 2015, 43, 1359-1365. [CrossRef]

26. Omoregbe, O.; Danh, H.T.; Abidin, S.Z.; Setiabudi, H.D.; Abdullah, B.; Vu, K.B.; Vo, D.V.N. Influence of Lanthanide Promoters on Ni/SBA-15 Catalysts for Syngas Production by Methane Dry Reforming. Procedia Eng. 2016, 148, 1388-1395. [CrossRef]

27. Rahbar Shamskar, F.; Meshkani, F.; Rezaei, M. Preparation and characterization of ultrasound-assisted co-precipitated nanocrystalline La-, $\mathrm{Ce}-, \mathrm{Zr}$-promoted $\mathrm{Ni}-\mathrm{Al}_{2} \mathrm{O}_{3}$ catalysts for dry reforming reaction. J. $\mathrm{CO}_{2}$ Util. 2017, 22, 124-134. [CrossRef]

28. Yao, L.; Galvez, M.E.; Hu, C.; Da Costa, P. Mo-promoted Ni/ $\mathrm{Al}_{2} \mathrm{O}_{3}$ catalyst for dry reforming of methane. Int. J. Hydrog. Energy 2017, 42, 23500-23507. [CrossRef]

29. Zhang, S.; Shi, C.; Chen, B.; Zhang, Y.; Zhu, Y.; Qiu, J.; Au, C. Catalytic role of $\beta-\mathrm{Mo}_{2} \mathrm{C}$ in DRM catalysts that contain Ni and Mo. Catal. Today 2015, 258, 676-683. [CrossRef] 
30. Abdollahifar, M.; Haghighi, M.; Babaluo, A.A.; Talkhoncheh, S.K. Sono-synthesis and characterization of bimetallic $\mathrm{Ni}-\mathrm{Co} / \mathrm{Al}_{2} \mathrm{O}_{3}-\mathrm{MgO}$ nanocatalyst: Effects of metal content on catalytic properties and activity for hydrogen production via $\mathrm{CO}_{2}$ reforming of $\mathrm{CH} 4$. Ultrason. Sonochem. 2016, 31, 173-183. [CrossRef]

31. Ma, Q.; Sun, J.; Gao, X.; Zhang, J.; Zhao, T.; Yoneyama, Y.; Tsubaki, N. Ordered mesoporous alumina-supported bimetallic Pd-Ni catalysts for methane dry reforming reaction. Catal. Sci. Technol. 2016, 6, 6542-6550. [CrossRef]

32. $\mathrm{Fu}, \mathrm{X}$.; $\mathrm{Su}, \mathrm{H}$.; Yin, W.; Huang, Y.; Gu, X. Bimetallic molybdenum nitride $\mathrm{Co}_{3} \mathrm{Mo}_{3} \mathrm{~N}$ : A new promising catalyst for $\mathrm{CO}_{2}$ reforming of methane. Catal. Sci. Technol. 2017, 7, 1671-1678. [CrossRef]

33. Ray, K.; Sengupta, S.; Deo, G. Reforming and cracking of $\mathrm{CH}_{4}$ over $\mathrm{Al}_{2} \mathrm{O}_{3}$ supported Ni, Ni-Fe and Ni-Co catalysts. Fuel Process. Technol. 2017, 156, 195-203. [CrossRef]

34. Farooqi, A.S.; Al-Swai, B.M.; Binti Ruslan, F.H.; Mohd Zabidi, N.A.; Saidur, R.; Faua'Ad Syed Muhammad, S.A.; Abdullah, B. Syngas production via dry reforming of methane over Nibased catalysts. IOP Conf. Ser. Mater. Sci. Eng. 2020, 736, 042007. [CrossRef]

35. Habibi, N.; Wang, Y.; Arandiyan, H.; Rezaei, M. Biogas Reforming for Hydrogen Production: A New Path to High-Performance Nickel Catalysts Supported on Magnesium Aluminate Spinel. ChemCatChem 2016, 8, 3600-3610. [CrossRef]

36. Akbari, E.; SM, A.; Rezaei, M. Synthesis gas production over highly active and stable nanostructured $\mathrm{Ni}-\mathrm{MgO}-\mathrm{Al}_{2} \mathrm{O}_{3}$ catalysts in dry reforming of methane: Effects of Ni contents. Fuel 2017, 194, 171-179. [CrossRef]

37. Lanzafame, P.; Perathoner, S.; Centi, G.; Gross, S.; Hensen, E.J.M. Grand challenges for catalysis in the Science and Technology Roadmap on Catalysis for Europe: Moving ahead for a sustainable future. Catal. Sci. Technol. 2017, 7, 5182-5194. [CrossRef]

38. Capezzuto, P.; Cramarossa, F.; D'Agostino, R.; Molinari, E. Contribution of vibrational excitation to the rate of carbon dioxide dissociation in electrical discharges. J. Phys. Chem. 1976, 80, 882-888. [CrossRef]

39. Czernichowski, A. Electrically assisted conversion of carbon dioxide into synthesis gas. In Greenhouse Gas Control Technologies; Eliasson, B., Riemer, P., Wokaun, A., Eds.; Elsevier: Amsterdam, Switzerland, 1999; pp. 385-443. ISBN 9780080553030.

40. Grosu, F.P.; Bologa, A.M.; Paur, H.R.; Bologa, M.K.; Motorin, O.V. Generalization of the Townsend current-voltage characteristics of a corona discharge. Surf. Eng. Appl. Electrochem. 2014, 50, 306-310. [CrossRef]

41. Chung, W.-C.; Chang, M.-B. Review of catalysis and plasma performance on dry reforming of $\mathrm{CH}_{4}$ and possible synergistic effects. Renew. Sustain. Energy Rev. 2016, 62, 13-31. [CrossRef]

42. Yang, Y. Methane conversion and reforming by nonthermal plasma on pins. Ind. Eng. Chem. Res. 2002, 41, 5918-5926. [CrossRef]

43. Li, M.W.; Tian, Y.L.; Xu, G.H. Characteristics of carbon dioxide reforming of methane via alternating current (AC) corona plasma reactions. Energy Fuels 2007, 21, 2335-2339. [CrossRef]

44. Seyed-Matin, N.; Jalili, A.H.; Jenab, M.H.; Zekordi, S.M.; Afzali, A.; Rasouli, C.; Zamaniyan, A. DC-pulsed plasma for dry reforming of methane to synthesis gas. Plasma Chem. Plasma Process. 2010, 30, 333-347. [CrossRef]

45. Aziznia, A.; Bozorgzadeh, H.R.; Seyed-Matin, N.; Baghalha, M.; Mohamadalizadeh, A. Comparison of dry reforming of methane in low temperature hybrid plasma-catalytic corona with thermal catalytic reactor over $\mathrm{Ni} / \gamma-\mathrm{Al}_{2} \mathrm{O}_{3}$. J. Nat. Gas Chem. 2012, 21, 466-475. [CrossRef]

46. Kogelschatz, U. Dielectric-barrier Discharges: Their History, Discharge Physics, and Industrial Applications. Plasma Chem. Plasma Process. 2003, 23, 1-46. [CrossRef]

47. Zou, J.J.; Zhang, Y.P.; Liu, C.J.; Li, Y.; Eliasson, B. Starch-enhanced Synthesis of Oxygenates from Methane and Carbon Dioxide using Dielectric-barrier Discharges. Plasma Chem. Plasma Process. 2003, 23, 69-82. [CrossRef]

48. Wang, Q.; Yan, B.-H.; Jin, Y.; Cheng, Y. Dry Reforming of Methane in a Dielectric Barrier Discharge Reactor with $\mathrm{Ni} / \mathrm{Al}_{2} \mathrm{O}_{3}$ Catalyst: Interaction of Catalyst and Plasma. Energy Fuels 2009, 23, 4196-4201. [CrossRef]

49. Morgan, W.L. A critical evaluation of low-energy electron impact cross sections for plasma processing modeling. II: $\mathrm{Cl}_{4}, \mathrm{SiH}_{4}$, and $\mathrm{CH}_{4}$. Plasma Chem. Plasma Process. 1992, 12, 477-493. [CrossRef]

50. McConkey, J.W.; Malone, C.P.; Johnson, P.V.; Winstead, C.; McKoy, V.; Kanik, I. Electron impact dissociation of oxygen-containing molecules-A critical review. Phys. Rep. 2008, 466, 1-103. [CrossRef]

51. Leclair, L.R.; Mc Conkey, J.W. On O(1S) and $\mathrm{CO}\left(\mathrm{a} 3 \mathrm{Pi}\right.$ ) production from electron impact dissociation of $\mathrm{CO}_{2}$. J. Phys. B At. Mol. Opt. Phys. 1994, 27, 4039-4055. [CrossRef]

52. Kozàk, T.; Bogaerts, A. Splitting of $\mathrm{CO}_{2}$ by vibrational excitation in non-equilibrium plasmas: A reaction kinetics model. Plasma Sources Sci. Technol. 2014, 23, 045004. [CrossRef] 
53. Yao, S.L.; Okumoto, M.; Nakayama, A.; Suzuki, E. Plasma Reforming and Coupling of Methane with Carbon Dioxide. Energy Fuels 2001, 15, 1295-1299. [CrossRef]

54. Li, X.-S.; Zhu, B.; Shi, C.; Xu, Y.; Zhu, A.-M. Carbon dioxide reforming of methane in kilohertz spark-discharge plasma at atmospheric pressure. AIChE J. 2011, 57, 2854-2860. [CrossRef]

55. Chung, W.C.; Lee, Y.E.; Chang, M.B. Syngas production via plasma photocatalytic reforming of methane with carbon dioxide. Int. J. Hydrog. Energy 2019, 44, 19153-19161. [CrossRef]

56. Tu, X.; Whitehead, J.C. Plasma-catalytic dry reforming of methane in an atmospheric dielectric barrier discharge: Understanding the synergistic effect at low temperature. Appl. Catal. B Environ. 2012, 125, 439-448. [CrossRef]

57. Xu, C.; Tu, X. Plasma-assisted methane conversion in an atmospheric pressure dielectric barrier discharge reactor. J. Energy Chem. 2013, 22, 420-425. [CrossRef]

58. Khoja, A.H.; Tahir, M.; Amin, N.A.S. Dry reforming of methane using different dielectric materials and DBD plasma reactor configurations. Energy Convers. Manag. 2017, 144, 262-274. [CrossRef]

59. Tu, X.; Whitehead, J.C. Plasma dry reforming of methane in an atmospheric pressure AC gliding arc discharge: Co-generation of syngas and carbon nanomaterials. Int. J. Hydrog. Energy 2014, 39, 9658-9669. [CrossRef]

60. Mao, S.; Tan, Z.; Zhang, L.; Huang, Q. Plasma-assisted biogas reforming to syngas at room temperature condition. J. Energy Inst. 2018, 91, 172-183. [CrossRef]

61. Khoja, A.H.; Tahir, M.; Amin, N.A.S. Recent developments in non-thermal catalytic DBD plasma reactor for dry reforming of methane. Energy Convers. Manag. 2019, 183, 529-560. [CrossRef]

62. Snoeckx, R.; Bogaerts, A. Plasma technology-A novel solution for $\mathrm{CO}_{2}$ conversion? Chem. Soc. Rev. 2017, 46, 5805-5863. [CrossRef] [PubMed]

63. Takaki, K.; Chang, J.; Kostov, K.G. Atmospheric pressure of nitrogen plasmas in a ferroelectric packed bed barrier discharge reactor. Part I. Modeling. IEEE Trans. Dielectr. Electr. Insul. 2004, 11, 481-490. [CrossRef]

64. Kanazawa, S.; Akamine, S.; Hirakawa, H.; Nomoto, Y. Decomposition of Toluene by a Dielectric Barrier Discharge Reactor with a Catalytic Coating Electrode. Fluid Flow Mach. 2000, 107, 65-74.

65. Butterworth, T.; Allen, R.W.K. Plasma-catalyst interaction studied in a single pellet DBD reactor: Dielectric constant effect on plasma dynamics. Plasma Sources Sci. Technol. 2017, 26, 065008. [CrossRef]

66. Mehta, P.; Barboun, P.; Go, D.B.; Hicks, J.C.; Schneider, W.F. Catalysis Enabled by Plasma Activation of Strong Chemical Bonds: A Review. ACS Energy Lett. 2019, 4, 1115-1133. [CrossRef]

67. Peeters, F.J.J.; Yang, R.; van de Sanden, M.C.M. The relation between the production efficiency of nitrogen atoms and the electrical characteristics of a dielectric barrier discharge. Plasma Sources Sci. Technol. 2015, 24, 045006. [CrossRef]

68. Hrycak, B.; Czylkowski, D.; Jasiński, M.; Dors, M.; Mizeraczyk, J. Hydrogen Production via Synthetic Biogas Reforming in Atmospheric-Pressure Microwave (915 MHz) Plasma at High Gas-Flow Output. Plasma Chem. Plasma Process. 2019, 39, 695-711. [CrossRef]

69. Czylkowski, D.; Hrycak, B.; Jasiński, M.; Dors, M.; Mizeraczyk, J. Microwave plasma-based method of hydrogen production via combined steam reforming of methane. Energy 2016, 113, 653-661. [CrossRef]

70. Czylkowski, D.; Hrycak, B.; Jasiński, M.; Dors, M.; Mizeraczyk, J. Atmospheric pressure low-power microwave microplasma source for deactivation of microorganisms. Eur. Phys. J. Appl. Phys. 2013, 61. [CrossRef]

71. Mizeraczyk, J.; Urashima, K.; Jasinski, M.; Dors, M. Hydrogen production from gaseous fuels by plasmas-A review. Int. J. Plasma Environ. Sci. Technol. 2014, 8, 89-97.

72. Homola, T.; Pongrác, B.; Zemánek, M.; Šimek, M. Efficiency of Ozone Production in Coplanar Dielectric Barrier Discharge. Plasma Chem. Plasma Process. 2019, 39, 1227-1242. [CrossRef]

73. Corke, T.C.; Post, M.L.; Orlov, D.M. Single dielectric barrier discharge plasma enhanced aerodynamics: Physics, modeling and applications. Exp. Fluids 2009, 46, 1-26. [CrossRef]

74. Goujard, V.; Tatibouët, J.-M.; Batiot-Dupeyrat, C. Use of a non-thermal plasma for the production of synthesis gas from biogas. Appl. Catal. A Gen. 2009, 353, 228-235. [CrossRef]

75. Li, Y.; Liu, C.-J.; Eliasson, B.; Wang, Y. Synthesis of Oxygenates and Higher Hydrocarbons Directly from Methane and Carbon Dioxide Using Dielectric-Barrier Discharges: Product Distribution. Energy Fuels 2002, 16, 864-870. [CrossRef]

76. Wang, Q.; Yan, B.-H.; Jin, Y.; Cheng, Y. Investigation of Dry Reforming of Methane in a Dielectric Barrier Discharge Reactor. Plasma Chem. Plasma Process. 2009, 29, 217-228. [CrossRef]

77. Song, H.K.; Lee, H.; Choi, J.W.; Na, B.K. Effect of electrical pulse forms on the $\mathrm{CO}_{2}$ reforming of methane using atmospheric dielectric barrier discharge. Plasma Chem. Plasma Process. 2004, 24, 57-72. [CrossRef] 
78. Scapinello, M.; Martini, L.M.; Dilecce, G.; Tosi, P. Conversion of $\mathrm{CH}_{4} / \mathrm{CO}_{2}$ by a nanosecond repetitively pulsed discharge. J. Phys. D Appl. Phys. 2016, 49. [CrossRef]

79. Wang, X.; Gao, Y.; Zhang, S.; Sun, H.; Li, J.; Shao, T. Nanosecond pulsed plasma assisted dry reforming of CH4: The effect of plasma operating parameters. Appl. Energy 2019, 243, 132-144. [CrossRef]

80. Cheng, H.; Fan, J.; Zhang, Y.; Liu, D.; Ostrikov, K.K. Nanosecond pulse plasma dry reforming of natural gas. Catal. Today 2020, 351, 103-112. [CrossRef]

81. Kim, H.-H.; Teramoto, Y.; Negishi, N.; Ogata, A. A multidisciplinary approach to understand the interactions of nonthermal plasma and catalyst: A review. Catal. Today 2015, 256, 13-22. [CrossRef]

82. Chung, W.-C.; Pan, K.-L.; Lee, H.-M.; Chang, M.-B. Dry Reforming of Methane with Dielectric Barrier Discharge and Ferroelectric Packed-Bed Reactors. Energy Fuels 2014, 28, 7621-7631. [CrossRef]

83. Takaki, K.; Takahashi, S.; Mukaigawa, S.; Fujiwara, T.; Sugawara, K.; Sugawara, T. Influence of Pellet Shape of Ferro-Electric Packed-Bed Plasma Reactor on Ozone Generation and NO Removal. Int. J. Plasma Environ. Sci. Technol. 2009, 3, 28-34.

84. Gómez-Ramírez, A.; Cotrino, J.; Lambert, R.M.; González-Elipe, A.R. Efficient synthesis of ammonia from $\mathrm{N}_{2}$ and $\mathrm{H}_{2}$ alone in a ferroelectric packed-bed DBD reactor. Plasma Sources Sci. Technol. 2015, 24, 065011. [CrossRef]

85. Gómez-Ramírez, A.; Montoro-Damas, A.M.; Cotrino, J.; Lambert, R.M.; González-Elipe, A.R. About the enhancement of chemical yield during the atmospheric plasma synthesis of ammonia in a ferroelectric packed bed reactor. Plasma Process. Polym. 2017, 14, 1600081. [CrossRef]

86. Taheraslani, M.; Gardeniers, H. High-Resolution SEM and EDX Characterization of Deposits Formed by $\mathrm{CH}_{4+}$ Ar DBD Plasma Processing in a Packed Bed Reactor. Nanomaterials 2019, 9, 589. [CrossRef] [PubMed]

87. Cheng, D.; Zhu, X.; Ben, Y.; He, F.; Cui, L.; Liu, C. Carbon dioxide reforming of methane over $\mathrm{Ni} / \mathrm{Al}_{2} \mathrm{O}_{3}$ treated with glow discharge plasma. Catal. Today 2006, 115, 205-210. [CrossRef]

88. Liu, C.; Zou, J.; Yu, K.; Cheng, D.; Han, Y.; Zhan, J.; Ratanatawanate, C.; Jang, B.W.-L. Plasma application for more environmentally friendly catalyst preparation. Pure Appl. Chem. 2006, 78, 1227-1238. [CrossRef]

89. Taheraslani, M.; Gardeniers, H. Coupling of $\mathrm{CH}_{4}$ to $\mathrm{C}_{2}$ hydrocarbons in a packed bed DBD plasma reactor: The effect of dielectric constant and porosity of the packing. Energies 2020, 13, 468. [CrossRef]

90. Tu, X.; Gallon, H.J.; Whitehead, J.C. Plasma-assisted reduction of a NiO/ $\mathrm{Al}_{2} \mathrm{O}_{3}$ catalyst in atmospheric pressure H2/Ar dielectric barrier discharge. Catal. Today 2013, 211, 120-125. [CrossRef]

91. Chang, J.-S.; Kostov, K.G.; Urashima, K.; Yamamoto, T.; Okayasu, Y.; Kato, T.; Iwaizumi, T.; Yoshimura, K. Removal of NF/sub 3/ from semiconductor-process flue gases by tandem packed-bed plasma and adsorbent hybrid systems. IEEE Trans. Ind. Appl. 2000, 36, 1251-1259. [CrossRef]

92. Carreon, M.L. Plasma catalysis: A brief tutorial. Plasma Res. Express 2019, 1, 043001. [CrossRef]

93. Zhu, F.; Zhang, H.; Yan, X.; Yan, J.; Ni, M.; Li, X.; Tu, X. Plasma-catalytic reforming of $\mathrm{CO}_{2}$-rich biogas over $\mathrm{Ni} / \gamma-\mathrm{Al}_{2} \mathrm{O}_{3}$ catalysts in a rotating gliding arc reactor. Fuel 2017, 199, 430-437. [CrossRef]

94. Song, H.K.; Choi, J.-W.; Yue, S.H.; Lee, H.; Na, B.-K. Synthesis gas production via dielectric barrier discharge over $\mathrm{Ni} / \gamma-\mathrm{Al}_{2} \mathrm{O}_{3}$ catalyst. Catal. Today 2004, 89, 27-33. [CrossRef]

95. Brune, L.; Ozkan, A.; Genty, E.; Visart De Bocarmé, T.; Reniers, F. Dry reforming of methane via plasma-catalysis: Influence of the catalyst nature supported on alumina in a packed-bed DBD configuration. J. Phys. D Appl. Phys. 2018, 51. [CrossRef]

96. Ozkan, A.; Dufour, T.; Silva, T.; Britun, N.; Snyders, R.; Bogaerts, A.; Reniers, F. The influence of power and frequency on the filamentary behavior of a flowing DBD-Application to the splitting of $\mathrm{CO}_{2}$. Plasma Sources Sci. Technol. 2016, 25, 025013. [CrossRef]

97. Ray, D.; Nepak, D.; Vinodkumar, T.; Subrahmanyam, C. g- $\mathrm{C}_{3} \mathrm{~N}_{4}$ promoted DBD plasma assisted dry reforming of methane. Energy 2019, 183, 630-638. [CrossRef]

98. Michielsen, I.; Uytdenhouwen, Y.; Bogaerts, A.; Meynen, V. Altering conversion and product selectivity of dry reforming of methane in a dielectric barrier discharge by changing the dielectric packing material. Catalysts 2019, 9, 51. [CrossRef]

99. Nguyen, H.H.; Kim, K.S. Combination of plasmas and catalytic reactions for $\mathrm{CO}_{2}$ reforming of $\mathrm{CH} 4$ by dielectric barrier discharge process. Catal. Today 2015, 256, 88-95. [CrossRef]

100. Mei, D.; Ashford, B.; He, Y.L.; Tu, X. Plasma-catalytic reforming of biogas over supported Ni catalysts in a dielectric barrier discharge reactor: Effect of catalyst supports. Plasma Process. Polym. 2017, 14, 1600076. [CrossRef] 
101. Khoja, A.H.; Tahir, M.; Saidina Amin, N.A. Evaluating the Performance of a Ni Catalyst Supported on $\mathrm{La}_{2} \mathrm{O}_{3}-\mathrm{MgAl}_{2} \mathrm{O}_{4}$ for Dry Reforming of Methane in a Packed Bed Dielectric Barrier Discharge Plasma Reactor. Energy Fuels 2019, 33, 11630-11647. [CrossRef]

102. Chung, W.C.; Tsao, I.Y.; Chang, M.B. Novel plasma photocatalysis process for syngas generation via dry reforming of methane. Energy Convers. Manag. 2018, 164, 417-428. [CrossRef]

103. Khoja, A.H.; Tahir, M.; Amin, N.A.S.; Javed, A.; Mehran, M.T. Kinetic study of dry reforming of methane using hybrid DBD plasma reactor over $\mathrm{La}_{2} \mathrm{O}_{3}$ co-supported $\mathrm{Ni} / \mathrm{MgAl}_{2} \mathrm{O}_{4}$ catalyst. Int. J. Hydrog. Energy 2020, 45, 12256-12271. [CrossRef]

104. Zheng, X.; Tan, S.; Dong, L.; Li, S.; Chen, H. Plasma-assisted catalytic dry reforming of methane: Highly catalytic performance of nickel ferrite nanoparticles embedded in silica. J. Power Sources 2015, 274, 286-294. [CrossRef]

105. Khoja, A.H.; Tahir, M.; Amin, N.A.S. Cold plasma dielectric barrier discharge reactor for dry reforming of methane over $\mathrm{Ni} / \gamma-\mathrm{Al}_{2} \mathrm{O}_{3}-\mathrm{MgO}$ nanocomposite. Fuel Process. Technol. 2018, 178, 166-179. [CrossRef]

106. Krawczyk, K.; Młotek, M.; Ulejczyk, B.; Schmidt-Szałowski, K. Methane conversion with carbon dioxide in plasma-catalytic system. Fuel 2014, 117, 608-617. [CrossRef]

107. Jin, L.; Li, Y.; Lin, P.; Hu, H. $\mathrm{CO}_{2}$ reforming of methane on $\mathrm{Ni} / \gamma-\mathrm{Al}_{2} \mathrm{O}_{3}$ catalyst prepared by dielectric barrier discharge hydrogen plasma. Int. J. Hydrog. Energy 2014, 39, 5756-5763. [CrossRef]

108. Ray, D.; Manoj Kumar Reddy, P.; Subrahmanyam, C. Glass Beads Packed DBD-Plasma Assisted Dry Reforming of Methane. Top. Catal. 2017, 60, 869-878. [CrossRef]

109. Chen, G. Progress in Plasma-Assisted Catalysis for Carbon Dioxide Reduction. In Plasma Chemistry and Gas Conversion; Wang, L., Ed.; IntechOpen: Rijeka, Croatia, 2018; ISBN 978-1-78984-841-0.

110. Whitehead, J.C.; Nozaki, T. Plasma Catalysis. Fundamentals and Applications; Springer: Cham, Switzerland, 2019.

111. Whitehead, J.C. Plasma catalysis: A solution for environmental problems. Pure Appl. Chem. 2010, 82, 1329-1336. [CrossRef]

112. Allah, Z.A.; Whitehead, J.C. Plasma-catalytic dry reforming of methane in an atmospheric pressure AC gliding arc discharge. Catal. Today 2015, 256, 76-79. [CrossRef]

113. Tu, X.; Gallon, H.J.; Twigg, M.V.; Gorry, P.A.; Whitehead, J.C. Dry reforming of methane over a $\mathrm{Ni} / \mathrm{Al}_{2} \mathrm{O}_{3}$ catalyst in a coaxial dielectric barrier discharge reactor. J. Phys. D Appl. Phys. 2011, 44, 274007. [CrossRef]

114. Einaga, H.; Ogata, A. Benzene oxidation with ozone over supported manganese oxide catalysts: Effect of catalyst support and reaction conditions. J. Hazard. Mater. 2009, 164, 1236-1241. [CrossRef] [PubMed]

115. Xi, Y.; Reed, C.; Lee, Y.-K.; Oyama, S.T. Acetone Oxidation Using Ozone on Manganese Oxide Catalysts. J. Phys. Chem. B 2005, 109, 17587-17596. [CrossRef] [PubMed]

116. Ye, Z.; Giraudon, J.-M.; De Geyter, N.; Morent, R.; Lamonier, J.-F. The Design of MnOx Based Catalyst in Post-Plasma Catalysis Configuration for Toluene Abatement. Catalysts 2018, 8, 91. [CrossRef]

117. Fan, X.; Zhu, T.; Sun, Y.; Yan, X. The roles of various plasma species in the plasma and plasma-catalytic removal of low-concentration formaldehyde in air. J. Hazard. Mater. 2011, 196, 380-385. [CrossRef] [PubMed]

118. Kim, H.H.; Tsubota, S.; Daté, M.; Ogata, A.; Futamura, S. Catalyst regeneration and activity enhancement of $\mathrm{Au} / \mathrm{TiO}_{2}$ by atmospheric pressure nonthermal plasma. Appl. Catal. A Gen. 2007, 329, 93-98. [CrossRef]

119. Huang, H.B.; Ye, D.Q.; Fu, M.L.; Feng, F. Da Contribution of UV light to the decomposition of toluene in dielectric barrier discharge plasma/photocatalysis system. Plasma Chem. Plasma Process. 2007, 27, 577-588. [CrossRef]

120. Mei, D.; Zhu, X.; Wu, C.; Ashford, B.; Williams, P.T.; Tu, X. Plasma-photocatalytic conversion of $\mathrm{CO}_{2}$ at low temperatures: Understanding the synergistic effect of plasma-catalysis. Appl. Catal. B Environ. 2016, 182, 525-532. [CrossRef]

121. Meng, S.; Wang, A.; He, P.; Song, H. Nonthermal Plasma-Assisted Photocatalytic Conversion of Simulated Natural Gas for High-Quality Gasoline Production near Ambient Conditions. J. Phys. Chem. Lett. 2020, 11, 3877-3881. [CrossRef]

122. Ma, J.; Ashfold, M.N.R.; Mankelevich, Y.A. Validating optical emission spectroscopy as a diagnostic of microwave activated $\mathrm{CH}_{4} / \mathrm{Ar} / \mathrm{H}_{2}$ plasmas used for diamond chemical vapor deposition. J. Appl. Phys. 2009, 105, 043302. [CrossRef]

123. Bashir, M.; Rees, J.M.; Bashir, S.; Zimmerman, W.B. Characterization of atmospheric pressure microplasma produced from argon and a mixture of argon-ethylenediamine. Phys. Lett. Sect. A Gen. At. Solid State Phys. 2014, 378, 2395-2405. [CrossRef] 
124. Zhou, H.; Watanabe, J.; Miyake, M.; Ogino, A.; Nagatsu, M.; Zhan, R. Optical and mass spectroscopy measurements of $\mathrm{Ar} / \mathrm{CH}_{4} / \mathrm{H}_{2}$ microwave plasma for nano-crystalline diamond film deposition. Diam. Relat. Mater. 2007, 16, 675-678. [CrossRef]

125. Kane, S.N.; Mishra, A.; Dutta, A.K. Preface: International Conference on Recent Trends in Physics (ICRTP 2016). J. Phys. Conf. Ser. 2016, 755, 011001. [CrossRef]

126. Denysenko, I.B.; Xu, S.; Long, J.D.; Rutkevych, P.P.; Azarenkov, N.A.; Ostrikov, K. Inductively coupled $\mathrm{Ar} / \mathrm{CH}_{4} / \mathrm{H}_{2}$ plasmas for low-temperature deposition of ordered carbon nanostructures. J. Appl. Phys. 2004, 95, 2713-2724. [CrossRef]

127. Liu, D.; Fisher, E.R. Surface interactions of C3 radicals during the deposition of fluorocarbon and hydrocarbon films. J. Vac. Sci. Technol. A Vac. Surf. Film. 2007, 25, 1519-1523. [CrossRef]

128. Gordillo-Vázquez, F.J.; Camero, M.; Gómez-Aleixandre, C. Spectroscopic measurements of the electron temperature in low pressure radiofrequency $\mathrm{Ar} / \mathrm{H}_{2} / \mathrm{C}_{2} \mathrm{H}_{2}$ and $\mathrm{Ar} / \mathrm{H}_{2} / \mathrm{CH}_{4}$ plasmas used for the synthesis of nanocarbon structures. Plasma Sources Sci. Technol. 2006, 15, 42-51. [CrossRef]

129. Griem, H.R. Principles of Plasma Spectroscopy; Cambridge University Press: Cambridge, UK, 1997; ISBN 9780521455046.

130. Sohbatzadeh, F.; Safari, R.; Etaati, G.R.; Asadi, E.; Mirzanejhad, S.; Hosseinnejad, M.T.; Samadi, O.; Bagheri, H. Characterization of diamond-like carbon thin film synthesized by RF atmospheric pressure plasma $\mathrm{Ar} / \mathrm{CH}_{4}$ jet. Superlattices Microstruct. 2016, 89, 231-241. [CrossRef]

131. Fisher, A.; Hill, S. Alternative and Mixed Gas Plasmas. In Inductively Coupled Plasma Spectrometry and Its Applications; Hill, S.J., Ed.; Blackwell: Hoboken, NJ, USA, 2007; pp. 226-245. ISBN 978-1-4051-3594-8.

132. Laux, C.O.; Spence, T.G.; Kruger, C.H.; Zare, R.N. Optical diagnostics of atmospheric pressure air plasmas. Plasma Sources Sci. Technol. 2003, 12, 125-138. [CrossRef]

133. Yuan, X.; Ding, X.; Zhao, Z.; Zhan, X.; Duan, Y. Performance evaluation of a newly designed DC microplasma for direct organic compound detection through molecular emission spectrometry. J. Anal. At. Spectrom. 2012, 27, 2094-2101. [CrossRef]

134. Stere, C.E.; Adress, W.; Burch, R.; Chansai, S.; Goguet, A.; Graham, W.G.; Hardacre, C. Probing a non-thermal plasma activated heterogeneously catalyzed reaction using in situ DRIFTS-MS. ACS Catal. 2015, 5, 956-964. [CrossRef]

135. Sakamoto, T.; Matsuura, H.; Akatsuka, H. Spectroscopic study on the vibrational populations of N2 C П3 and В ПЗ states in a microwave nitrogen discharge. J. Appl. Phys. 2007, 101, 023307. [CrossRef]

136. Kinoshita, M.; Fuyuto, T.; Akatsuka, H. Measurement of vibrational and rotational temperature in spark-discharge plasma by optical emission spectroscopy: Change in thermal equilibrium characteristics of plasma under air flow. Int. J. Engine Res. 2019, 20, 746-757. [CrossRef]

137. Akatsuka, H. Optical Emission Spectroscopy Measurement of Processing Plasmas. IEEJ Trans. Fundam. Mater. 2010, 130, 892-898. [CrossRef]

138. Rodrigues, A.; Tatibouët, J.-M.; Fourré, E. Operando DRIFT Spectroscopy Characterization of Intermediate Species on Catalysts Surface in VOC Removal from Air by Non-thermal Plasma Assisted Catalysis. Plasma Chem. Plasma Process. 2016, 36, 901-915. [CrossRef]

139. Jia, Z.; Rousseau, A. Sorbent track: Quantitative monitoring of adsorbed VOCs under in-situ plasma exposure. Sci. Rep. 2016, 6, 31888. [CrossRef]

140. Stere, C.; Chansai, S.; Gholami, R.; Wangkawong, K.; Singhania, A.; Goguet, A.; Inceesungvorn, B.; Hardacre, C. A design of a fixed bed plasma DRIFTS cell for studying the NTP-assisted heterogeneously catalysed reactions. Catal. Sci. Technol. 2020, 10, 1458-1466. [CrossRef]

141. Nair, S.A.; Nozaki, T.; Okazaki, K. In situ Fourier Transform Infrared (FTIR) study of nonthermal-plasmaassisted methane oxidative conversion. Ind. Eng. Chem. Res. 2007, 46, 3486-3496. [CrossRef]

142. Sumizawa, H.; Yamada, H.; Tonokura, K. Real-time monitoring of nitric oxide in diesel exhaust gas by mid-infrared cavity ring-down spectroscopy. Appl. Phys. B 2010, 100, 925-931. [CrossRef]

143. Sur, R.; Sun, K.; Jeffries, J.B.; Socha, J.G.; Hanson, R.K. Scanned-wavelength-modulation-spectroscopy sensor for $\mathrm{CO}, \mathrm{CO}_{2}, \mathrm{CH}_{4}$ and $\mathrm{H}_{2} \mathrm{O}$ in a high-pressure engineering-scale transport-reactor coal gasifier. Fuel 2015, 150, 102-111. [CrossRef]

144. Goldenstein, C.S.; Spearrin, R.M.; Jeffries, J.B.; Hanson, R.K. Infrared laser-absorption sensing for combustion gases. Prog. Energy Combust. Sci. 2017, 60, 132-176. [CrossRef] 
145. Chang, L.S.; Jeffries, J.B.; Hanson, R.K. Mass Flux Sensing via Tunable Diode Laser Absorption of Water Vapor. AIAA J. 2010, 48, 2687-2693. [CrossRef]

146. Liu, X.; Jeffries, J.B.; Hanson, R.K.; Hinckley, K.M.; Woodmansee, M.A. Development of a tunable diode laser sensor for measurements of gas turbine exhaust temperature. Appl. Phys. B 2006, 82, 469-478. [CrossRef]

147. Rao, W.; Wen, M.; Xin, M.; Song, J.; Feng, G.; Wang, G. Simultaneous temperature, $\mathrm{H}_{2} \mathrm{O}$ concentration and pressure measurement in a scramjet combustor with combined operation mode using wavelength modulation spectroscopy. In Proceedings of the Fifth International Symposium on Laser Interaction with Matter, Changsha, China, 11-14 November 2018; Volume 11046.

148. Song, L.; Liu, L.; Yang, Y.; Guo, Q.; Xi, J. An optical sensor for hydrogen sulfide detection in open path using WMS-2f/1f technique. Optoelectron. Lett. 2016, 12, 465-468. [CrossRef]

149. Kamimoto, T.; Deguchi, Y.; Zhang, N.; Nakao, R.; Takagi, T.; Zhang, J.-Z. Real-time 2D Concentration Measurement of $\mathrm{CH}_{4}$ in Oscillating Flames Using CT Tunable Diode Laser Absorption Spectroscopy. J. Appl. Nonlinear Dyn. 2015, 4, 295-303. [CrossRef]

150. Deguchi, Y.; Kamimoto, T.; Kiyota, Y. Time resolved 2D concentration and temperature measurement using CT tunable laser absorption spectroscopy. Flow Meas. Instrum. 2015, 46, 312-318. [CrossRef]

151. Slaets, J.; Aghaei, M.; Ceulemans, S.; Van Alphen, S.; Bogaerts, $\mathrm{A}$. $\mathrm{CO}_{2}$ and $\mathrm{CH}_{4}$ conversion in "real" gas mixtures in a gliding arc plasmatron: How do $\mathrm{N}_{2}$ and $\mathrm{O}_{2}$ affect the performance? Green Chem. 2020, 22, 1366-1377. [CrossRef]

152. Yang, T.; Shen, J.; Ran, T.; Li, J.; Chen, P.; Yin, Y. Understanding $\mathrm{CO}_{2}$ decomposition by thermal plasma with supersonic expansion quench. Plasma Sci. Technol. 2018, 20, 065502. [CrossRef]

Publisher's Note: MDPI stays neutral with regard to jurisdictional claims in published maps and institutional affiliations. 